\title{
PLC Fuzzy PID Controller of MPPT of Solar Energy Converter
} ABDULLAH J. H. AL GIZI *

\author{
${ }^{1}$ Thi-Qar Technical Collage, Electromechanical Engineering Department \\ Southern Technical University \\ Thi-Qar Nasiriyah High Way Street Bridge Thi-Qar Technical Collage \\ IRAQ
}

\begin{abstract}
Development of the Maximum-Power-Point-Tracking (MPPT) scheme for solar mounts and rectifiers leftovers interesting. We design of high-sensitive fuzzy (HSF) Proportional-Integral-Derivative (PIDC) controller by means of Matlab and Programmable-Logic-Controllers (PLCs) for an adjusted of the MPPT scheme. This proposal is founded on a synergistic mixture of the Radial-Basis-Function-Neural Network (RBF-NN), Genetic Algorithm (GA), and Sugeno-Fuzzy-Logic (SFL) systems. The finest limits of PIDC and MPPT are strong-minded through optimization, wherever RBF-NN is adjusted by means of GA to reach the best key. Also, RBF-NN is rummage-sale to improve the PID limits (got from GA) for scheming HSFL-PIDC of the MPPT scheme. The HSFL-PIDC controller is extra planned to transfer in PLCs (STEP 75.5) for implementing the photovoltaic (PV) scheme. The all-inclusive scheme is extra tuned by solar limits under numerous operational circumstances to advance the solar recital in terms of accusing and correcting. The recital of the planned analog employed MPPT controller is assessed by interfacing it with a hardware prototype of dual photovoltaic (PV) scheme. The mixture controller configured the regulator signal founded on the interaction and in that way reduces the voltage mistake and the oscillation in the voltage regulator process. The achieved scheme is established to be well-organized and robust in refining solar charging and rectifying capability .
\end{abstract}

Key-Words: - GA, HSF, HSFL-PIDC, MPPT, PIDC, PLC, RBF-NN, SFL

Received: June 5, 2020. Revised: December 7, 2020. Accepted: December 20, 2020. Published: January 4, 2021.

\section{Introduction}

In recent years, dedicated efforts have been made to achieve efficient solar photovoltaic (PV) systems with improved performance. In particular, as a strategy for performance improvement, solar tracking system is researched in-depth. Engin value and Engin vector [1] projected a switch procedure that could recover the presentation and dependability of the two-axis solar follower. [2]. It was accomplished into two stages including the hardware and software development. Elagib and Osman [3] presented the design of a microcontroller based solar tracking system via solar maps, which could predict the exact apparent position (latitudes) of the sun. This system contained the solar tracking mechanical structure together with the associated electronic circuits. It established the way of regulatory a sun following panel with an entrenched microchip scheme [4].
Mechanization control schemes are widespread in discipline and knowledge. The archetypal hardware expedient used in engineering regulator is Programmable-Logic-Controllers (PLC) that regulators many industrial schemes. Request of Simulink sub-systems from MATLAB to STEP 75.5 for employing PLC use a amount of regulator loops accountable for maintenance the actions fineness of the process are significantly augmented with evergrowing complications of modern procedure plants. PLC is browbeaten to regulator plants or manufacturing gear"s such as water and leftover regulator, energy, oil and gas purifying, etc. to cite a few [5].

Underneath present widespread automaticgeneration-control (AGC) focused on local power grid, a large-capacity coal-fired supercritical (SC) power unit often purposes under wide-range changeable load conditions as proposed by [6]. 
[7] The vast normal of instinctive managers used to recompense industrial events are PI or PID type. This book extensively amasses; using a joint representation, modification rules for these managers future from 1935 to 2008 and the adjustment rules are prudently proprietary. The helping of the adjustment to the speed prejudiced by the person's preceding best location (P) is Difference amongst Rapidity Regulator DC Motor Using GA and PSO-PID Procedure [8]. The performance of PI and fuzzy bosses in speed controller of IM drive are simulated, Li-Xin Wang, A Order in Fuzzy Schemes and Regulator

Unintended

Vector Skillful Induction Motor Drive are presented by [9]. Managers for Unintended Field Oriented Regulator by means of these dual first circumstances and induction motor equations, we have the chief equations of unintended vector control [10].Normally, a fuzzy PID boss is industrial using PLC for responsibility the problematic of a set-point weight manager in the main density group scheme. An brainy ranked corresponding regulator plan is definitely practical by[6]. [11] Are presented To overwhelmed this disadvantage, a PSO founded fuzzy manager limit optimization is obtainable in this paper. The PSO procedure is used to find the best fuzzy limits for minimizing the impartial functions. Since of being fuzziness and existence of doubt in input variables to fuzzy schemes, and also their easy application, fuzzy managers are introduced as one of valuable optimization tools in manufacturing particularly in DC engines are projected by [12].In this paper we use Ziegler-Nichols modification process for modification of a Proportional-Integral (P-I) and Integral-Proportional (I-P) manager for a DC motor to regulator its speed[13].

The philosophy presented by Zadeh deals with the doubt and fuzziness connected info regarding several limits [14].The main detached of the AVR scheme is to regulator the fatal voltage by regulating the generator exciter voltage. It necessity keep-track of the generator fatal voltage all the time underneath any load disorder by upholding the voltage within pre-determined bounds [15]. Notwithstanding much labors in emerging advanced regulator schemes, the regulator of classical integrated-PLC-Fuzzy PID Simulink applied AVR system is far from being understood [16]. The PID owning proportional, integral and differential, constants optimally regulators the AVR scheme. Computational procedures such as GA and fuzzy logic are rummage-sale for logical resolution[17]. A change fuzzy logic style for decisive the optimum PID controller limits in AVR scheme is industrialized to get on-line PID limits under numerous working circumstances [18].

The development of an image-based sun position sensor and the algorithm was aimed to locate the sun precisely using image processing [19]. To verify the performance of the sun-tracking system an image tracking platform was established using an image-based sun position sensor, and a controller with embedded image processing algorithm. The performance testing was conducted in the laboratory. The results revealed that the proposed sun tracking system could overcome the problem of unstable tracking in cloudy weather and achieved a tracking accuracy of $0.04^{\circ}$. Ahmad et al [20] intended and automatic a device that could attain low power ingesting. Advanced, an smart solar following scheme founded on entrenched microcontroller LPC2131 was employed [21] which might recover the photo-electric change competence of the solar-cell-array by following the drive of the sun finished 2-axis moving engines' revolution.

Xie and Zhang [22] considered a triple-junction solar cell to achieve the highest efficiency. Moreover, the system required the concentration and accurate tracking to maintain the light focusing on the solar cells during the sun movement throughout the day. The tracking system was built with two-axis driven by motor with angle sensor feedback. The two angles were determined by solar positions which were calculated from solar geometric algorithm. A new design of sun tracker for more transformation of solar energy was presented [23].

The solar vigor has been enhanced in fresher manner rendering to the cumulative rank of re-newable dynamisms by emerging a samplebiaxial sun follower [24]. Three procedures were used for following the sun. The first one allowable the plane to interchange in circular organizes over small ranges for discovery the point with the best voltage in terms of field of work and location recurrently. Second algorithm aided to regulate the slope of the voltage and used it to find its way. The last one is alike the second process which assisted to find some fitting points that are distinct in dissimilar times. Seme et al [25] careful 2-axis sun following scheme for a PV scheme. The routes of this scheme were strong-minded via optimism. Additionally, call of Simulink sub-systems from MATLAB to STEP 75.5 can be united to PLC [26]. PLC regulator 
scheme is specially intended for industrial setting request with outstanding stability and dependability. The good-looking features of PLC such as simple, supple, easy scheme configuration with low cost, low upkeep and running cost make them appropriate for employment. PLC being a particular computer which borders a set of inputs to sensors and a set of outputs to actuators can regulator the plant by execution various functions such as logic, sequencing, timing, counting and mathematics. PLC regulator scheme is a versatile scheme consisting of several PLCs and computers coupled composed for operation. The project of an lively solar panel dualaxis sun following system with all-out power point following fuzzy supervisor was future [27]. This system tracked the maximum solar power point and oriented the solar panel toward the Sun to enhance the efficiency of the PV generation system. The design of a two-axis standalone rotary sun tracker [28] was presented and implemented. Xiaofang and Wencheng [29] applied a new tracking system based on concentrated photovoltaic (CPV). The following accuracy and compassion of the solar tracker was found to have important inspiration on the lighting rate and power generation amount of the industrialized CPV scheme. The CPV solar follower founded on ARM could track the sun mostly using the CMOS sensor. A sample of 2-axis solar following scheme founded on a PIC microcontroller was also available [30]. The parabolic indicator or parabolic plate is built everywhere two feed diameter to capture the solar vigour. The focus of the parabolic reflector was hypothetically intended up to an infinitesimally minor point for achieving tremendously high temperature. This 2axis auto-tracking scheme was fabricated using PIC 16F84A micro-controller. Dasgupta et al. [31] labelled the project and application of a original 2axis sun following scheme which used no outside bright sensors to brand PV-cell opposite in the way of all-out radioactivity to endorse scheme capability. The real-world employment of solar boards as the sensors was the main novelty of the proposed design. The mixture of the solar cells electrical qualities was rummage-sale to limit the insolation parameters. Jiao et al. [32-34] also proposed a 2-axis sun-tracking scheme that kept the PV panel upright to the sun light by absolute and relative location sensors signal examination.

The paper numbers [1-4], [19-34], proposed the sun tracking system controller, dual-axis solar tracking development and Experimental Study for a Two-Axis Sun Tracker,whereas the the references
[5-18] explanation for different techniques for control speeds, voltage position by fuzzy ,GA,PSO ,LQR and PLC - base fuzzy .In current years, devoted efforts have been made to reach effective solar photovoltaic (PV) schemes with enhanced performance. The paper numbers [28-29] to the end references explanation the hybrid of different techniques for example neural-fuzzy, Discrete-time ripple correlation, reference adaptive control, wavelet radial basis function neural networks, Radial basis function network based on time variant multi-objective particle swarm optimization and Differential Evolution algorithm based Radial Basis Function Networks for classification problems in particular, as a strategy for performance improvement, solar tracking system is researched in-depth to reach the improvement, solar tracking system efficiency and quality.

Diverse light sensing methods have been exploited such as LDR, image-based sun position sensor using image processing, Pyrometer, phototransistor, CMOS, and solar panels as a light sensor. Every research used different control strategy to perform tracking, where each of them was chosen to be suitable with its own system capabilities. Control is the way to lead the apparatus in a certain algorithm, where different control procedure was utilized following two major paths including closed or open loop control system. In open-loop tracking scheme, the tracker performed the calculation to identify the position of the sun and determined the rotational angles of the two tracking axes. A specific suntracking formula was utilized in order to drive the solar collector towards the sun.

This paper theme the project of a HSFL-PIDC and the best process in MPPT comptroller scheme of rules of rules beneficial for solar energy change and modification. The novel projected scheme joint the GA, RBF-NN besides SFL patterns. The carrying into military action of the projected analogimplemented MPPT comptroller is assessed by implementing a computer hardware paradigm of dual PV system. 
Terminology

$\begin{array}{llll}M P P T & \begin{array}{l}\text { Maximum- } \\ \text { Power-Point- } \\ \text { Tracking }\end{array} & \boldsymbol{f}_{\text {best }} & \begin{array}{l}\text { Uppermost } \\ \text { worth }\end{array} \\ K_{d}, \begin{array}{l}\text { Percentage } \\ \text { constant, } \\ \text { difference } \\ \text { constant, and } \\ \text { essential } \\ \text { constant, } \\ K_{p}\end{array} & K_{\text {best }} & \begin{array}{l}\text { Separate with the } \\ \text { uppermost suitability worth } \\ \text { in the current gen. } \\ \text { of PID } \\ \text { controller }\end{array} & \\ & & \\ & \end{array}$
Amount of $K_{j}^{i}(g) \quad \begin{aligned} & \text { a actual amount in the } \\ & \text { Persons Gen. }\end{aligned}$ actual appreciated GA

(N), Amount of Peers Rand( an consistently dispersed ) chance amount in $[0,1]$

$\left(P_{c}\right) \quad$ Cusp Likelihood $q \quad$ separate with the uppermost suitability worth by means of: Regulate the finest standards of $f$ and $K$ by means of the appearance

$\left(\theta_{r}\right)$

Generational

$L$

Improvement

( $\left.t_{g}\right) \quad$ Producing Period Constant

$P_{i} \quad$ Replicated amount of the $I$ the separate Which can be printed

\section{$\left(\boldsymbol{P}_{m}\right) \quad$ Change}

Likelihood

$K_{m}(g)$ dual persons as of the and present populace

$K_{n}(g)$

consistently dispersed

fit(.) Suitability function

$\mathrm{o}_{1}$ and
$\mathrm{O}_{2}^{\prime}$

g-th

Gen.

$f_{\text {best }}$

Best fitness-value
$\left.K_{j}^{\min }\right)$

chance number in $[0,1]$

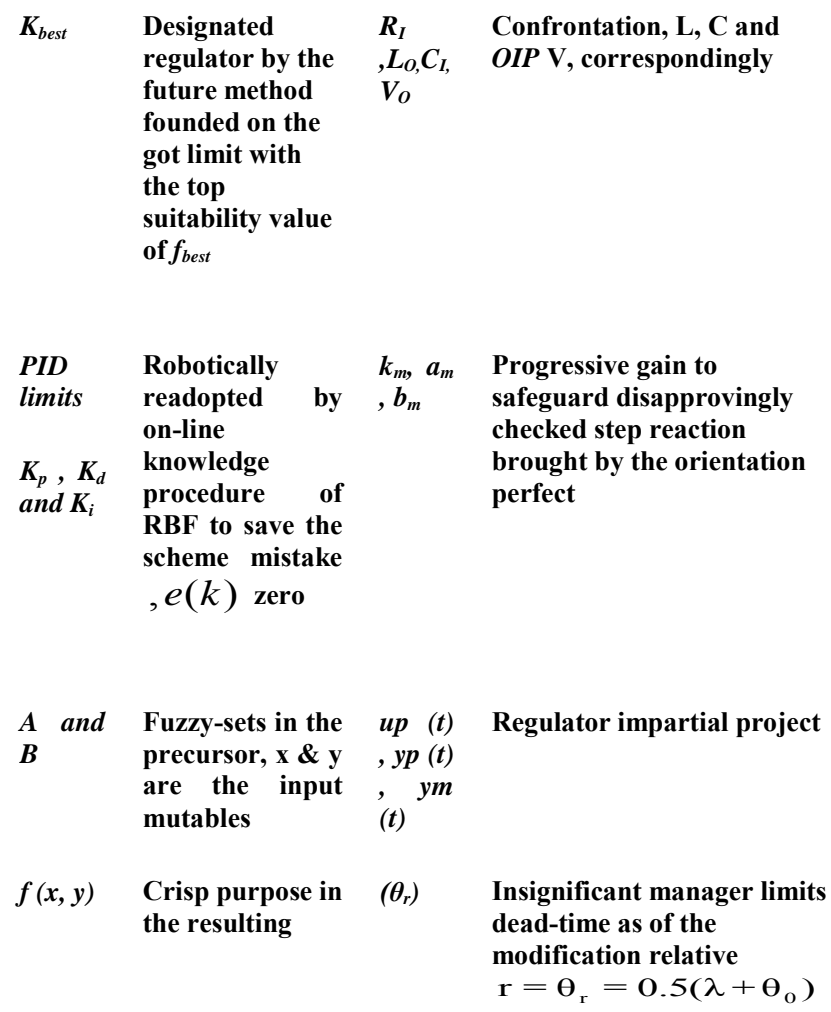

Insignificant manager limits dead-time as of the modification relative $\mathbf{r}=\boldsymbol{\theta}_{\mathrm{r}}=0.5\left(\lambda+\boldsymbol{\theta}_{\mathrm{o}}\right)$

Regulator impartial project

$W_{i} \quad$ Lowest of the (a) Shut round time continuous association for a set-point modification purposes, input that got for each rule

RCC Ripple Association Regulator

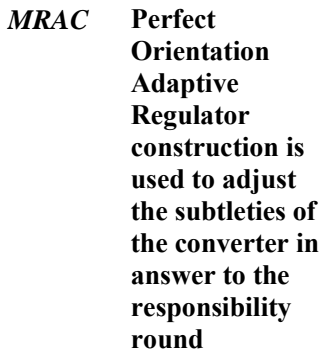




\section{Radial Basis Function Networks}

Moody et al. Projected RBF-NN with a single hidden layer to impersonator the methodical preparation of preventive modification in the human mind [35]. The RBF-NN crops the sturdiest reply near the midpoint of the Gaussian-kernel function where apiece hidden node in the input data space container be stored as a local sensor and the RBF$\mathrm{NN}$ is considered as a local approximation model for the skillful processes [36-38]. The graphic of RBF-NN is shown in Fig. 1. The bring up-to-date process for the adaptive PID founded RBF can be expressed as,

$$
\begin{aligned}
& \Delta k_{p}=\mu \cdot e(k) \cdot e_{p}(k) \cdot \sum_{j=1}^{m} w_{j} h_{j} \frac{c_{j 3}-u(k)}{\sigma_{j}^{2}} \\
& \Delta k_{i}=\mu \cdot e(k) \cdot e_{i}(k) \cdot \sum_{j=1}^{m} w_{j} h_{j} \frac{c_{j 3}-u(k)}{\sigma_{j}^{2}} \\
& \Delta k_{d}=\mu . e(k) \cdot e_{d}(k) \cdot \sum_{j=1}^{m} w_{j} h_{j} \frac{c_{j 3}-u(k)}{\sigma_{j}^{2}}
\end{aligned}
$$

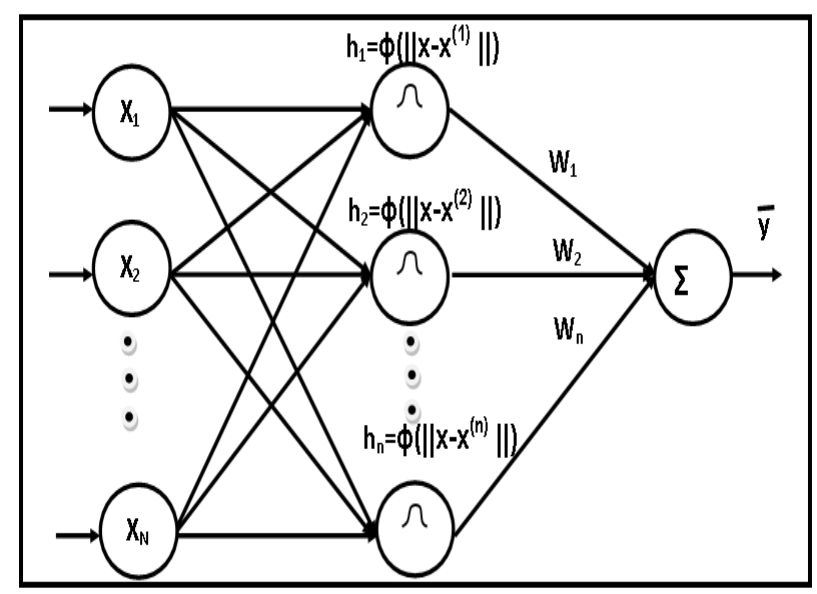

Fig. 1.Schematics of RBF neural network structure

The PID limits such as integral-gain $\left(\mathrm{K}_{\mathrm{i}}\right)$, the proportional-gain $\left(\mathrm{K}_{\mathrm{p}}\right)$ and the derivative-gain $\left(\mathrm{K}_{\mathrm{d}}\right)$ are mechanically adopted by RBF on-line learning procedure to uphold the scheme error $e(k)=0$. Two instructions obtainable by Matlab namely Newrb and newrbe are used to project the RBF-NN which Newrb adds neurons stage by stage until the goalmouth is hit with long exercise time with negligible error and newrbe projects a net very rapidly with zero error [39, 40]. In the exercise progression, the attained steps are: (i) neurons number in the concealed layer, (ii) the organizes of the midpoint of RBF function (iii) and the radius (spread) of each RBF functions in each measurement.

\section{MPPT}

\subsection{Modeling Of MPPT System}

The description of the Mppt system in section 3.1 is poor and should be extended.

Fig. 2 schematically exemplifies the dual level modified regulator process for the projected MPPT [41] scheme. At the first level, the ripple correlation control (RCC) is utilized to calculate the duty cycle of the converter, which is expected to deliver maximum available power to the load in the steady state. In the second control level, the model reference adaptive control (MRAC) structure is used to regulate the dynamics of the converter in response to the duty cycle calculated from RCC, which prevented the array voltage from transient oscillations after changes in solar insolation. The RCC level is responsible for handling the changes in solar insolation.

The tuning process of RCC must be fast enough to catch up to the changes in solar insolation. Therefore, the time constant of RCC is required to be smaller than that of the dynamics of insolation variations. Conversely, MRAC that is accountable for maintaining the optimal damping characteristics of the converter must have a much smaller time constant compared to the environmental changes. On top, the tuning process of MRAC must be fast enough to catch up to the changes in the operating point of the converter and the responses of RCC.

Thus, the time constant of MRAC is required to be much smaller than that of the RCC. The most significant difference between these two time constants allowed us to decouple the analyses for RCC and MRAC, and thereby greatly simplified the overall control design. It is customary to describe briefly salient features of MRAC to validate its coupling with RCC.

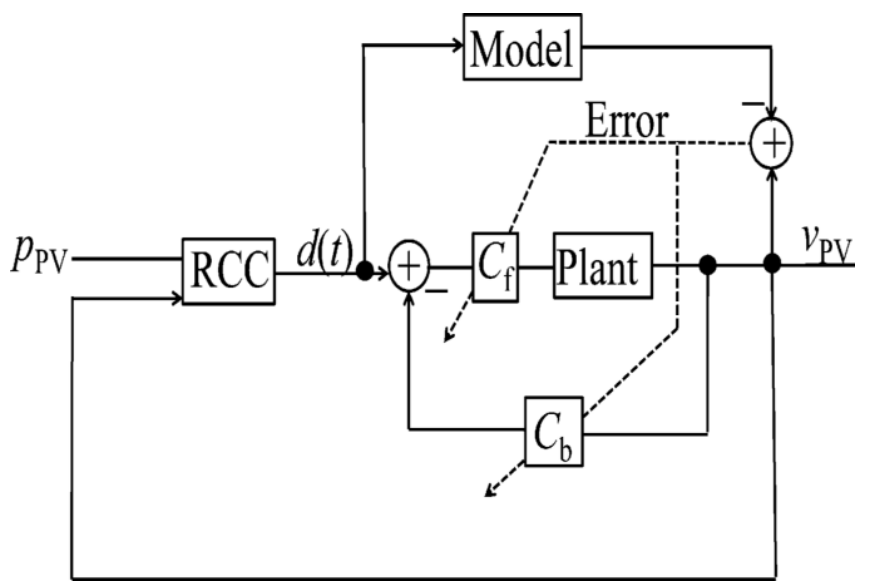

Fig. 2. Schematic diagram of the proposed MPPT system 
As above-mentioned, our recently industrialized dual-level MPPT switch procedure is contained of RCC [41-44] in the first level and MRAC [41] in the additional level. Fig. 2 obviously demonstrations that in the primary switch level the collection voltage VPV and influence PPV help as the contributions to the RCC component. The RCC computes the responsibility sequence that brings the all-out control to the weight in the stable national. The chief novelty of RCC is to usage the swapping wave characteristic to the converter to trouble the scheme and thus path the MPP [41]. The RCC is fundamentally an better variety of the $\mathrm{P} \& \mathrm{O}$ technique [41] excluding that the alarm is characteristic to the converter. Such a practice is beneficial because it refutes the need for outside electrical system to vaccinate the alarm. Besides, $\mathrm{RCC}$ has been established to meet asymptotically to the MPP with negligible supervisor difficulty and straight-forward circuit application [41]. The RCC is founded on the next observations: the creation of the period based offshoots of the collection voltage (V PV) and power (P PV) necessity be (i) greater than zero to the left of the MPP, (ii) less than zero to the right of the MPP, and (iii)precisely zero at the MPP obeying the control laws [41]:

$\frac{d p_{p v}}{d t} \frac{d v_{p v}}{d t}>0$ when $V_{P V}<V_{M}$,
$\frac{d p_{p v}}{d t} \frac{d v_{p v}}{d t}<0$ when $V_{P V}>V_{M}$
$\frac{d p_{p v}}{d t} \frac{d v_{p v}}{d t}=0$ when $V_{P V}=V_{M}$

These comments lead to the regulator law derived in[42]

$\frac{d d(t)}{d t}=k \frac{d p_{P V}}{d t} \frac{d p_{P V}}{d t}$

Where $\mathrm{k}$ is a constant called negative gain.

Referring to Fig. 2, the regulator rule in reckoning (7) container be situated qualitatively labeled as shadows: if $v P V$ upsurges and here is a subsequent upsurge of $P V$, the scheme $\mathrm{s}$ point of working is the left of the MPP and so $d(t)$ would reduction, causing an upsurge of $v P V$. If $p P V$ reductions after an upsurge in $\mathrm{v} P V$, then the scheme es functioning point is in the correct of the MPP and thus $d(t)$ necessity upsurge in instruction to decrease $\mathrm{v} P V$. Investigative equations (6) and (7), one can set the time-based copying of $d(t)$ to zero consequently that all-out control is attained. Fig. 3 displays PV the boost converter system.

Following the well-established theoretical basis of RCC [41], the optimal value of the duty cycle can be obtained in order to deliver maximum power in the steady state. The advantage of RCC over conventional algorithms such as $\mathrm{P} \& \mathrm{O}$ is that in the steady-state of RCC converges to the MPP while
P\&O oscillates around the MPP. Relative to FL and NNs, RCC is beneficial due to its economy and simple implementation procedure. In addition to steady-state analysis, one must also consider the transient response of the boost converter system so that the controller can rapidly converge to the theoretical MPP with minimal oscillation. Now we discuss the functioning of MRAC algorithm that prevents the array voltage mediated under-damped response.

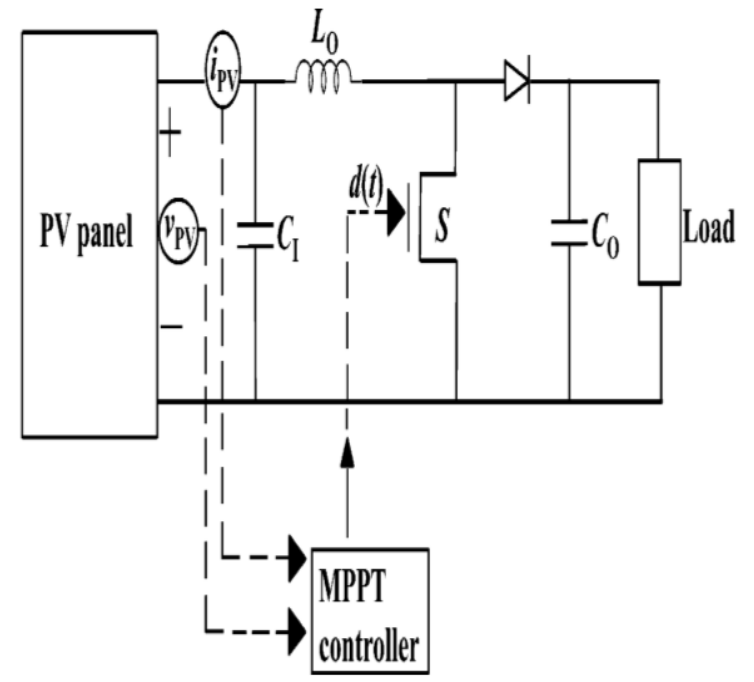

Fig.3.Circuit illustration of MPPT manager designed for the PV boost converter scheme

\subsection{Proposed MRAC Method}

Fig. 4 exhibitions the projected construction of MRAC scheme. The contribution to the complete scheme, $r(t)$, is the alteration in responsibility cycle as intended previous using RCC. The work typical agrees to the carry-over purpose (equation 5). Though, for suitability the sign is altered by increasing (-single) so that the vegetable perfect has only optimistic coefficient. The input /output of the vegetable is meant by up (t) and yp (t), correspondingly. Table 1 précises the time value of used boot converter parameter. Table 2 enlists the standards of adaptive manager limits Table 3 likens the values of insignificant phrase with actual manager limits. Table 4 summarizes the numerous transfer-functions and the variety of limit values for solar mechanisms 
Table 1. Values of boost converter parameter

\begin{tabular}{|l|l|}
\hline $\begin{array}{l}\text { Circuit } \\
\text { parameter }\end{array}$ & Value \\
\hline $\mathrm{R}_{\mathrm{I}}$ & $45 \Omega$ \\
\hline $\mathrm{L}_{\mathrm{O}}$ & $600 \mu \mathrm{H}$ \\
\hline $\mathrm{C}_{\mathrm{I}}$ & $100 \mu \mathrm{F}$ \\
\hline $\mathrm{V}_{\mathrm{O}}$ & $350 \mathrm{~V}$ \\
\hline
\end{tabular}

Table 2. Values of adaptive controller parameters

\begin{tabular}{|l|l|}
\hline Parameter & Value \\
\hline $\mathrm{k}_{\mathrm{p}}=\mathrm{V}_{\mathrm{o}} /\left(\mathrm{L}_{\mathrm{o}} \times \mathrm{C}_{\mathrm{I}}\right)$ & $\begin{array}{l}5.83 \times 10^{9} \quad \mathrm{~V} \\
(\mathrm{rad} / \mathrm{sec})^{2}\end{array}$ \\
\hline $\mathrm{a}_{\mathrm{p}}=1\left(\mathrm{R}_{1} \times \mathrm{C}_{\mathrm{I}}\right)$ & $222 \mathrm{rad} / \mathrm{sec}$ \\
\hline $\mathrm{b}_{\mathrm{p}}=1 /\left(\mathrm{L}_{\mathrm{o}} \times \mathrm{C}_{\mathrm{I}}\right)$ & $\begin{array}{l}1.67 \times 10^{7} \\
(\mathrm{rad} / \mathrm{sec})^{2}\end{array}$ \\
\hline $\mathrm{k}_{\mathrm{m}}$ & $\begin{array}{l}5.83 \times 10^{9} \quad \mathrm{~V} \\
(\mathrm{rad} / \mathrm{sec})^{2}\end{array}$ \\
\hline $\mathrm{a}_{\mathrm{m}}$ & $\begin{array}{l}8.17 \times 10^{3} \\
\mathrm{rad} / \mathrm{sec}\end{array}$ \\
\hline $\mathrm{b}_{\mathrm{m}}$ & $\begin{array}{l}1.67 \times 10^{7} \\
(\mathrm{rad} / \mathrm{sec})^{2}\end{array}$ \\
\hline$\Lambda$ & 1 \\
\hline $\mathrm{g}$ & 1 \\
\hline$\Gamma$ & $\begin{array}{l}5 \times \text { identity } \\
\text { matrix }\end{array}$ \\
\hline
\end{tabular}

Table 3. Contrast among the values of insignificant and actual manager limits

\begin{tabular}{|l|l|l|l|l|}
\hline & $\boldsymbol{\theta}_{\mathbf{0}}$ & $\boldsymbol{\theta}_{\mathbf{1}}$ & $\boldsymbol{\theta}_{\mathbf{2}}$ & $\boldsymbol{\theta}_{\mathbf{3}}$ \\
\hline Insignifica & 1.0 & - & - & - \\
nt manager & 0 & $7.95 \times 1$ & 22. & $3.00 \times 1$ \\
limits & & $0^{3}$ & 8 & $0^{-4}$ \\
\hline Updated & 1.0 & - & - & - \\
manager & 0 & $8.12 \times 1$ & 20. & $2.80 \times 1$ \\
limits & & $0^{3}$ & 4 & $0^{-4}$ \\
\hline
\end{tabular}

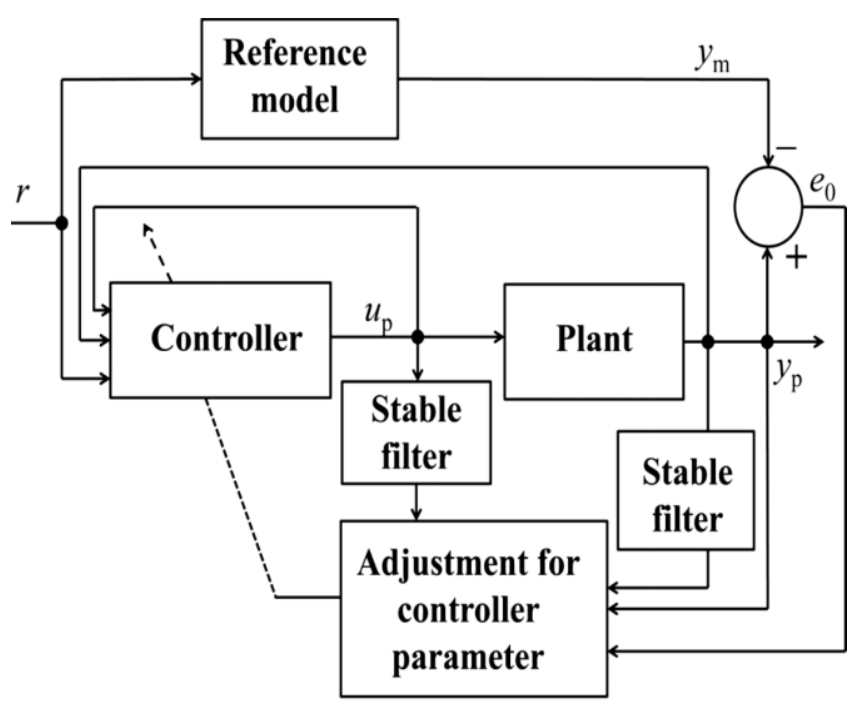

(a)

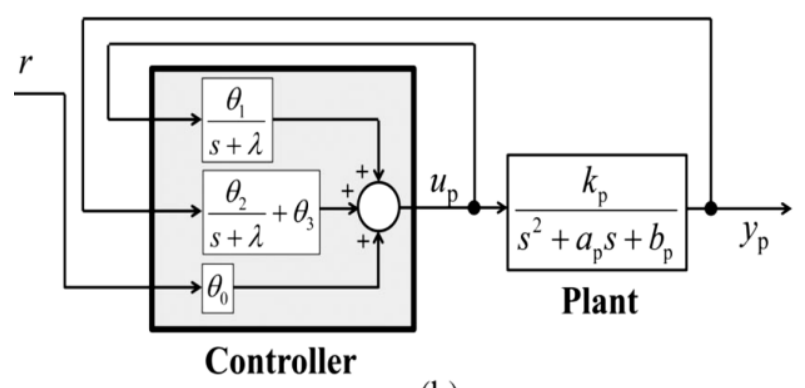

(b)

Fig. 4. Schematic presentation of the proposed: (a) MRAC structure and its (b) controller architecture

\subsection{Optimization of Controller Parameters}

The satisfactory process of the scheme is strongminded by the option of the finest PID control limits. Furthermore, the assortment problematic of the PID manager limits is careful as an optimisation problematic. The impartial purpose output,

$\operatorname{MinF}\left(\mathrm{K}_{\mathrm{d}}, K_{p}, K_{i}\right)=\left(1-e^{-\beta}\right)\left(O_{s h}+E_{s s}\right)+e^{-\beta}\left(t_{s}-t_{r}\right)$

The $\operatorname{MinF}\left(\mathrm{KP}, \mathrm{K}_{\mathrm{d}}, \mathrm{K}_{\mathrm{i}}\right)$ syndicates transient reply including rise more overshoot, settling time and steady-body politic error. The gratification of the fashionable wants can be attained by selecting the appropriate value of the allowance factor $\beta$. Consequently, the optimization problematic boils down to the next restraints,

$K_{p}^{\min } \leq K_{p} \leq K_{p}^{\max }, K_{i}^{\min } \leq K_{i} \leq K_{i}^{\max }, K_{d}^{\min } \leq K_{d} \leq K_{d}^{\max }$

Subsequent Devaraj et al. [45], GA is applied to enhance the values supervisor limits and the proposed GA is presented. 
Table 4. Numerous transfer-functions and the variety of limit values for solar mechanisms

\begin{tabular}{|c|c|c|}
\hline Components & Transfer & Parameter limits \\
\hline Plant & $T F_{p \text { pan }}=K_{p}^{2} / s+a_{p} s+b_{p}$ & $\begin{array}{l}K_{p}=V_{O} /\left(L_{O} \times C_{1}\right) \\
5.83 \times 10^{9} \quad \mathrm{~V} \quad(\mathrm{rad} / \mathrm{sec})^{2} \\
a_{p}=1 /\left(R_{1} \times C_{1}\right)\end{array}$ \\
\hline Controller in $r$ & $\theta_{r}=0.5\left(\lambda+\theta_{0}\right)$ & $\begin{array}{l}\mathbf{O}<\boldsymbol{\theta}_{O} \leq \mathbf{1} \\
\lambda=1\end{array}$ \\
\hline $\begin{array}{l}\text { Controller } \\
\text { feedback } y_{P}\end{array}$ & $y_{p}=\left(\theta_{2} / s+\lambda\right)+\theta_{3}$ & $\begin{array}{l}-22.8 \leq \theta_{2} \leq-20.4 \\
-3 \times 10^{-4} \leq \theta_{3} \leq-2.8 \times 10^{4}\end{array}$ \\
\hline Controller $u_{p}$ & $u_{p}=\theta_{1} / s+\lambda$ & $\begin{array}{l}-7.95 \times 10^{3} \leq \theta_{1} \leq-8.12 \times 10^{3} \\
\theta_{1} \cong-8.035 \times 10^{-3}\end{array}$ \\
\hline
\end{tabular}

\section{Proposed GA}

GA is documented as an actual and efficient technique to resolve the optimization difficulties. In contrast to the optimization methods, such as random search and replicated annealing, GA recital is larger that avoids local minima careful as a key issue in nonlinear schemes [17, 18].

\subsection{Genetic Algorithm Operators}

The Genetic-Algorithms are founded on the accepted selection instrument that lets existence of the rightest and make projected solutions by swapping info"s to attain the ideal solution. Afterward making the initial populace, the GA determines new persons by manufacturing progenies $^{\text {ee }}$ using the imitation, crossover and mutation operators, which substitute the old generation memberships and form the newfangled cohort. Once numerous cohorts are produced, the process finds the top chromosome that signifies the top or near optimal answer.

The chief GA workers such as cross-over, reproduction and mutation are browbeaten. The merging speed is skillful by applying numerous likelihoods on these workers. The project of the crossover and mutation workers are prudently managed due to their huge impact on the presentation of GA $[17,18]$. The particulars of the hereditary workers used in the future GA are exemplified in Table 4.

\subsubsection{Reproduction}

In the procedure of replica, folks are selected contingent on their fitness purpose, the higher the fitness is, more chance for an separate to be designated for the next cohort. Three main assortment approaches such as ranking technique, fitness stable selection and contest selection are utilized [45]. In this work, we employment the tournament assortment technique, where , $\mathrm{n}^{\text {ee }}$ persons are randomly designated from the populace and the best vale is chosen for extra genetic meting out. This process is recurrently done until the breeding pool is filled.

\subsubsection{Crossover}

The stuff of global search in GA is mostly strongminded by the crossover worker, which organizations two-parent-chromosomes to crop a novel one. The diversity of the chosen likelihood is naturally amongst $0.6-1.0$. One of the stimulating topographies of the crossover operators is the relative in the middle of the engendered chromosome and the location of mutually the parents. The produced new chromosome leftovers close to the parents in case mutually the parents are close to apiece other. Contrariwise, the search is more probable to be random [45].

\subsubsection{Mutation}

New chromosome is presented into the public for the alteration procedure. Alteration randomly makes an unimportant diversity in the chromosome info. However, for changeable alteration, the changeable takes a dependable random number amongst the inferior and higher bounds. In this study „unchanging mutates ${ }^{\text {ee }}$ employee is used.

\subsection{GA Application is adjusting limits of MMPPT PID}

The top PID manager limits are got via GA alteration of PID. Two main tunes such as sign of the outstanding variables (variable symbol) and groundwork of the fitness function are used in this process.

\subsection{Variable Representation}

The answers of all applicants are made in the genetic populace. The answer rudiments of PID 
controller modification problematic comprise limits $\mathrm{K}_{\mathrm{i}}, \mathrm{K}_{\mathrm{p}}$ and $\mathrm{K}_{\mathrm{d}}$. The direct picture of the answer variables decreases the processor space for storage the populace. The standards of these limit got from straight change of GA into the RBF package for the best modification of the PID manager limit are considerable for the thematic sweatshop process of MMPPT scheme.

\subsubsection{Fitness Function}

The answer for the presentation of every single applicant in the populace is assessed founded on its suitability which is clear as a non-negative rate to be exploited. Suitability is related in a conventional line with the rate of impartial purpose. The limit set of the separate assessment can be a strong-minded by means of reckoning (6) for the presentation criteria. The value of separate fitness is intended by the consequence of the performance standards via mutual calculation. The suitability, purpose is the performance of the sympathy criterion $\mathrm{F}\left(K P, K_{d}, K_{i}\right)$ given in equation (6). Thus, the minimization of presentation standards in eq. (6) can be distorted to the expansion of the fitness purpose as,

$$
\text { Fitness }=\frac{k}{F\left(\mathrm{~K}_{\mathrm{d}}, K_{p}, K_{i}\right) * I T A E}
$$

Where $k$ is a constant, ITAE is a period essential increased through the total error rate. This is rummage-sale to intensify the importance of $1 / \mathrm{F}$, which is usually small, so that, the genetic material suitability standards happen in a wider variety.

\section{Sugeno Fuzzy Model}

Newly, the fuzzy set philosophy was used in which a adjustable is a associate of unique or more sets with a association stated degree [45]. The fuzzy rule can be expressed as:

If $x$ is $A$ \& $y$ is $B$ then $z=f(x, y)$

where A \& B are fuzzy groups in the precursor, $x \& y$ are the participation mutable and $\mathrm{f}(\mathrm{x}, \mathrm{y})$ is a crunchy occupation in the resulting.

Initially, the least of the association occupations input $\left(w_{i}\right)$ is got for each rule, anywhere this rate is the gunfire rate for a specific rule. Furthermore, the general output is intended by a biased regular of separate rule productions by means of the formulation:

$$
z=\frac{\sum_{i=1}^{M} \omega_{i} z_{i}}{\sum_{i=1}^{M} \omega_{i}}
$$

The limits of PIDC below numerous working settings are strong-minded by the SF scheme.

\section{Functional Mechanisms For Application}

Fig. 5 demonstrations the whole useful device for the request. The response of the HSFL-PIDC manager in MATLAB/Simulink to the runtime on PLC (board scheme) is tested [26].
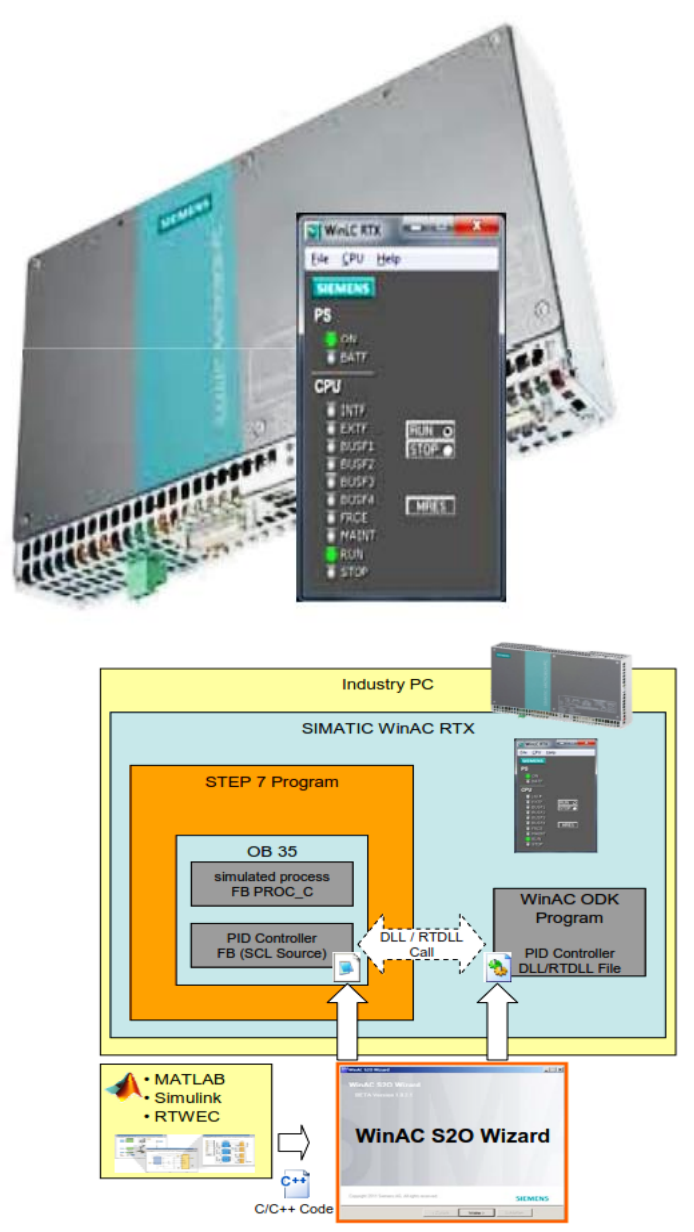

Fig. 5.Functional mechanism for the experimentation

\subsection{Information Categories}

Type change is prudently performed at the package borders due to dissimilar data type practice of STEP 7, WinAC ODK and the Actual Plant Entrenched Coder. The WinAC S2O Sorcerer knows the information kinds of the RTWEC $\mathrm{C} / \mathrm{C}++$ package and familiarizes the information in the WinAC ODK package and STEP 7 package (SCL foundation). Style alteration is attained during the implementation of WinAC S2O Sorcerer. The 
software rummage-sale to transmit the information from Matlab to PLC are MATLAB V7.11 (R2010b), Simulink V7.6, Actual Plant V7.6, Actual Workshop Entrenched Coder V5.6, MicrosoftVisual-Studio 2008 Expert, STEP V5.5, S7-SCL V5.3, WinAC ODK V4.2 and WinAC RTX 2010 on a PC scheme (SIMATIC IPC427C). Hardware counting SIMATIC IPC427C (MICROBOX PC) is rummage-sale in this trial. The $\mathrm{S} 7$ program shapes PG/PC interfaced Ethernet (192.168.2.200) and

IPC427C interfaced PROFINET CP1616 (192.168.2.10) are active.

The RGA procedure only needs the info of the suitability, purpose rate for each limit established. These dual procedures (RGA and RBF-NN) are functional to choose a good PID regulator limit set for the MMPT scheme as labeled beneath.

\section{Results And Discussion}

\subsection{Mythology to design fuzzy PLC PID controller}

\subsubsection{Development of a Sugeno Fuzzy Model to Design PID controller}

The applied and final boundary to circlet presentation container be submissive by understanding an indirect deceased time $\left(\theta_{\mathrm{r}}\right)$ since the change relative $r=\theta r=0.5\left(\lambda+\theta_{0}\right)$. The deceased period container be approached as the unique deceased period $\left(\theta_{0}\right)$ increased by a issue of 0.5 to the shut circlet period constant $(\lambda)$ for a set point alteration. For dangerous distress snub by a PID, rate of $\lambda$ is set equivalent to the unique deceased period. In this national, the dead time is equivalent to the unique deceased period. $r=\theta r=0.5\left(\lambda+\theta_{0}\right), \theta_{\mathrm{o}}=1, \lambda=1$. The top and combined errors for unmeasured step turbulences signify the nastiest case. The finest PID limits for real development are became by evolving SF logic prototypical, where, $\theta_{r}$ and $y p\left(\theta_{1}, \theta_{2}\right)$ are the contributions with $K_{p}, K_{i}$ and $K_{d}$ are the outputs. Eight fuzzy sets such as ,very low $(V L)^{\text {ee }}$, ,low $(L)^{\text {ee }}$ „,medium low $(M L)^{\text {ee }}$, ,medium $(M)^{\text {ee }}$, ,medium high $(M H)^{\text {ee }}$, ,high low $(H L)^{\text {ee }}$, ,high medium $(H M)^{\text {ee }}$ and ,high $(H)^{\text {ec }}$ are clear for the mutable $\theta_{r}$. Likewise, the fuzzy sets clear for the mutable $y p\left(\theta_{1}, \theta_{2}\right)$ are ,,very low $(V L)^{\text {ee }}$, ,low $(L)^{\text {ee }}$, ,medium low $(M L)^{\text {ee }}$, „,medium high $(M H)^{\text {ee }}$, ,high $(H)^{\text {ee }}$ and ,very high $(V H)^{e}$. They are related to meeting triangular involvement purposes. 
Table 5. The limits used to generate the Sugeno fuzzy rule

\begin{tabular}{|c|c|c|c|c|c|c|}
\hline & Very Low & Low & $\begin{array}{l}\text { Medium } \\
\text { Low }\end{array}$ & $\begin{array}{l}\text { Medium } \\
\text { High }\end{array}$ & High & Very high \\
\hline$r=\theta_{r}=0.5\left(\lambda+\theta_{0}\right)$ & 0.1 & 0.2 & 0.4 & 0.6 & 0.8 & 1 \\
\hline $\begin{array}{c}y_{P},-22.8 \leq \theta_{2} \leq-20.4 \\
-3 \times 10^{4} \leq \theta_{3} \leq-2.8 \times 10^{4}\end{array}$ & 0.55 & 0.6 & 0.7 & 0.8 & 0.9 & 1 \\
\hline \multicolumn{7}{|c|}{$u_{p}=\theta_{1} / s+\lambda, \theta_{1} \cong-8.035 \times 10^{3}$} \\
\hline \multicolumn{7}{|c|}{ (a) For proportional gain $K_{p}$} \\
\hline Low (-22.8)-3,0.55 & 0.7947 & 0.7253 & 0.9814 & 0.8045 & 0.7292 & 0.9062 \\
\hline Medium low(-22) (-2.933) & 0.9804 & 0.9822 & 0.5904 & 0.7195 & 0.9912 & 0.9541 \\
\hline Medium high (-21.2)(-2.866) & 0.9062 & 0.6500 & 0.6520 & 0.8759 & 0.8416 & 0.6931 \\
\hline $\operatorname{High}(-20.4)(-2.8)$ & 0.8651 & 0.9599 & 0.7977 & 0.9951 & 0.6197 & 0.8192 \\
\hline \multicolumn{7}{|c|}{ (b) For integral gain $K_{i}$} \\
\hline Low $(-22.8)$ & 0.4946 & 0.4990 & 0.4585 & 0.4961 & 0.4990 & 0.4804 \\
\hline Medium low(-22) & 0.5000 & 0.4883 & 0.4717 & 0.4907 & 0.4812000 & 0.4971 \\
\hline Medium high $(-21,2)$ & 0.4966 & 0.4861 & 0.4717 & 0.4995 & 0.4589 & 0.4834 \\
\hline $\operatorname{High}(-20.4)$ & 0.4980 & 0.4844 & 0.4941 & 0.4990 & 0.4726 & 0.4956 \\
\hline \multicolumn{7}{|c|}{ (c) For derivative gain $K_{d}$} \\
\hline Low $(-22.8)$ & 0.0428 & 0.0352 & 0.0757 & 0.0229 & 0.0150 & 0.0101 \\
\hline Medium low(-22) & 0.0010 & 0.0199 & 0.18443 & 0.0000 & 0.00110 & 0.0528 \\
\hline Medium high $(-21,2)$ & 0.0613 & 0.1674 & 0.0126 & 0.0463 & 0.00422 & 0.1076 \\
\hline $\operatorname{High}(-20.4)$ & 0.01660 & 0.0029 & 0.00023 & 0.0067 & 0.1049 & 0.270 \\
\hline
\end{tabular}

To express the table for fuzzy rule, the standards of $\theta_{r}$ are diverse from 0.7 to 1.0 in steps of 0.1 and the standards of $y p$ are various from 1 to 2 in steps of 0.2 . For apiece mixture of $\theta_{r}$ and $y p$, the future RBF regulation via GA is practical to get the best values of $K_{p}, K_{d}$ and $K_{i}$ in each times. The fuzzy rule is expressed for $K_{p}, K_{d}$ and $K_{i}$ and abridged in Table 5(a)-(c), correspondingly. Throughout real-time process, the standards of $\theta_{r}$ and $y p$ are strongminded. Using these standards of $\Theta r$ and $y p$, the finest value of $K_{p}, K_{d}$ and $K_{i}$ are designed by the fuzzy rule table and the FIS editor Surgeon inference scheme. Contingent on the initialization (FIS editor), the standards of inputs of the fuzzy logic manager are $\theta_{r}, y p$ and the outputs are $\left(K_{p}, K_{\mathrm{d}}\right.$ and $\left.K_{i}\right)$.

The scheme with three fuzzy logic controllers $\left(K_{p}\right.$, $K_{d}$ and $K_{i}$ ) and rule viewer are established, in which each controller has two inputs $\left(\Theta_{r}, y p\right)$ and each input has fuzzy established related with it. The input variability for $\theta r$ is $0.7 \leq \theta r \leq 1$ and $y p$ is $0.4 s<y p<1 s$.
The output standards of $K_{p}, K_{d}$ and $K_{i}$ be contingent on the difference of $\Theta r$ with admiration to yp

finished the output setting rule established on the tabularized values. The output has 72 fuzzy set rules for $K p, K d$ and $K i$, and 48 rules for each one limit as portrayed in Fig. 4 surface and rule viewer. For this value of $\theta_{r}$ and $\mathrm{y}_{\mathrm{p}}$, the best value of $K_{p}, K_{d}$ and $K_{i}$ can be calculated by means of the fuzzy rule table and the surgeon inference scheme. The best results are got with the next control limits for GA: the number of generation $=50$, population size $=30$, crossover $=0.6$, mutation probability $=0.001$. Also, by choosing the correct value of the allowance factor $\beta=1$, the presentation criterion can be complete to content the fashionable obligation. The software for the proposed RBF and GA is written using MATLAB and performed on a laptop Intel core(TM)2 Duo CPU 5550@1.83GHz. The GA disbursed $23.79 \mathrm{~s}$ to reach the best solution. 


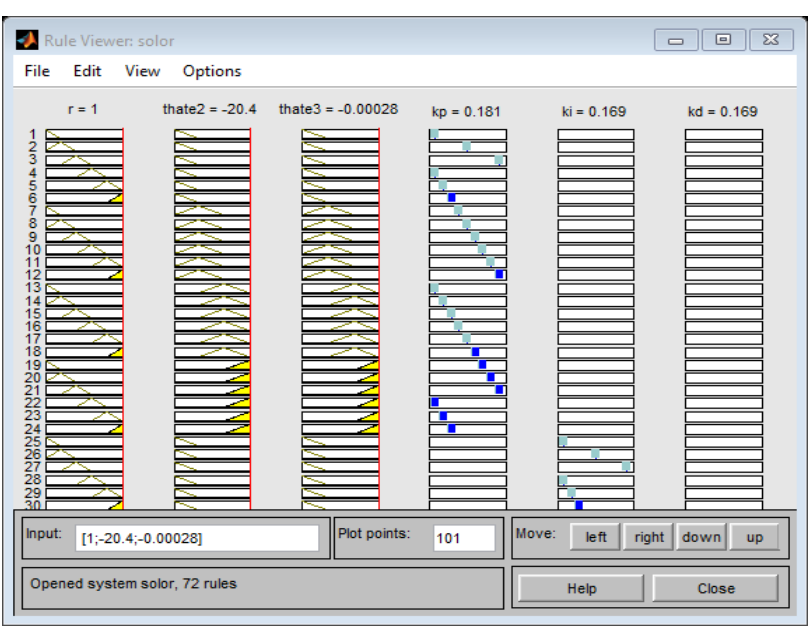

Fig. 6. Computer screen shot (the rule viewer) for the proposed Fuzzy controller of sun tracker scheme

\subsubsection{MPPT of PV Using HSFL-PIDC}

The MPPT scheme usages a DC to DC converter to recompense the production voltage of the solar board to save the electrical energy at the rate which make the most of the productive influence. MPP FLC actions the standards of the electrical energy and current at the production of the solar board, then computes the influence of the relative $(\mathrm{P}=\mathrm{VI})$ to excerpt the inputs of the manager. The crunchy production of the manager signifies the responsibility cycle of the pulse width inflection to change the dc to dc converter. Fig. 7. Shows the block illustration of the future MPPT scheme.

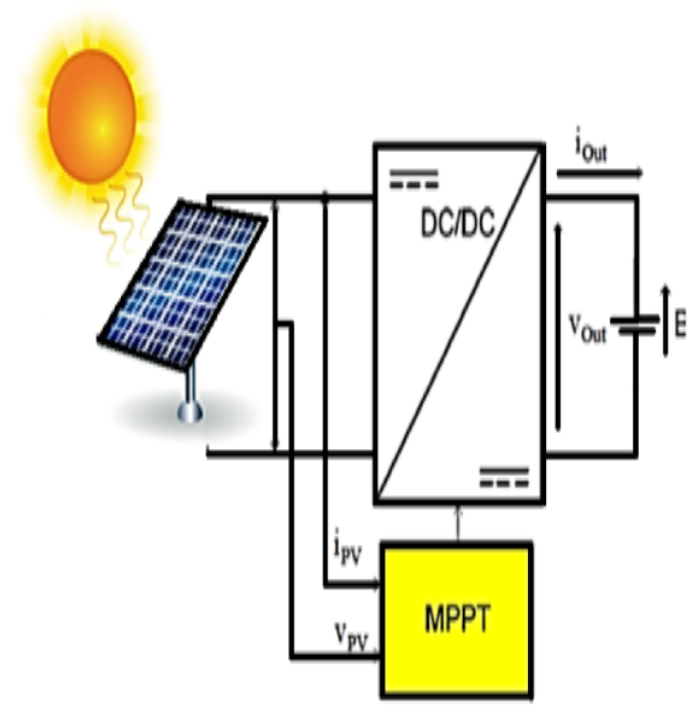

Fig. 7 . Diagram of MPPT scheme interfaced with PV solar board.

MPPT Fuzzy Logic Manager (FLC) inspects the production PV power at apiece example (time_k) and controls the variation in energy compared to electrical energy $(\mathrm{DP} / \mathrm{dev})$. If this rate is better than zero the supervisor variation the responsibility cycle of the Pulse Width Modulation(PWM) to upsurge the electrical energy pending the power is all-out or the value $(\mathrm{DP} / \mathrm{dev})=0$. Equally, $\mathrm{dp} / \mathrm{dv}$ is fewer than zero the manager vicissitudes the responsibility cycle of the PWM to reduce the voltage pending the power is all-out as exposed in Fig. 8.

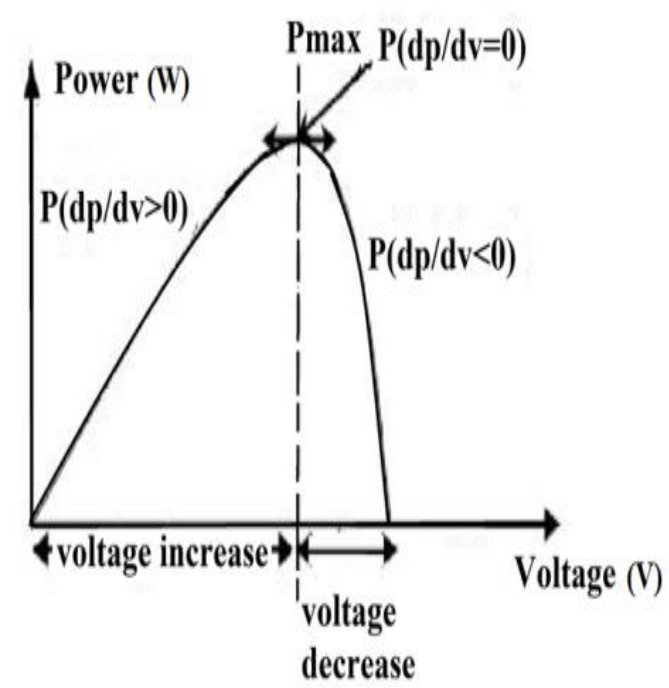

Fig. 8. Power-voltage characteristic of a PV module

FLC owns dual inputs $\theta_{\mathrm{r}}$ and $\mathrm{y}_{\mathrm{p}}\left(\Theta_{1}, \Theta_{2}\right)$. The applied and final boundary to loop presentation can be submitted by understanding an indirect dead period $\left(\theta_{\mathrm{r}}\right)$ from the change. The best PID limits for actual process are got by emerging SFL models with $K P$, $K_{i}$ and $K_{d}$ as the productions, nourishing to the pulse width inflection to regulator the DC/DC converter. The dual FLC input variables $\theta_{\mathrm{r}}$ and up $\left(\theta_{1}, \theta_{2}\right)$ attested $\mathrm{k}$ periods clear by:

$$
\text { Error }(\mathrm{k})=\frac{\mathrm{P}(\mathrm{K})-\mathrm{P}(\mathrm{K}-1)}{\mathrm{V}(\mathrm{K})-\mathrm{V}(\mathrm{K}-1)}
$$

Change_Error $(\mathrm{k})=\operatorname{Error}(\mathrm{k})-\operatorname{Error}(\mathrm{k}-1)$

(13)

Wherever $P(k)$ is the prompt energy of the photovoltaic producer. Input $\theta_{\mathrm{r}}(\mathrm{k})$ means if the weight process point at the prompt $k$ is situated on the right or on the left of the all-out influence point on the $P V$ typical. Also, input $y_{p}\left(\theta_{1}, \theta_{2}\right)$ couriers the touching way of this point. The imitation, originally the battery-operated is primary cleared and then invigorated together at a continuous current of 5.5 A. A humble current perfect is rummage-sale to duplicate the cordless fever. It is expected that refrigeration is chiefly through convection, and the boiler is majorly after the cordless interior resistance (R2). A normal $14 \mathrm{~V}$ lead-acid-battery is modeled by linking seven reproductions of the $2 \mathrm{~V}$ cordless cell block in sequence [46].

The best PID limits of the fuzzy implication is approved out via actual process and got by emerging 
SFL perfect for the MPP follower as showed in Fig.. $9(\mathrm{a}, \mathrm{b}, \mathrm{c})$. It is obvious that the signs are not flat, but they approved a constituent of the all-out power amid voltage \& current. The voltage variety altered from $12.5 \mathrm{~V}$ to $14 \mathrm{~V}$ and the current IL is varied amid 0 and 10 A throughout the inductance and -5 , +5 as throughout the capacitor at time $0.05 \mathrm{sec}$. The voltage sign (Fig. 10) ranges among $13.3-14.3 \mathrm{~V}$ at gazing and stable state at $13.4 \mathrm{~V}$ alike to the orientation signal, where the present signal advanced is varied amid 4.8-13 at staring and stable sate at 5.5 alike to the orientation signal showed this. Fuzzy logic supervisor with PWM sign has dual compensations to the inverter. First, it crops a flat, error-free sine-wave. Additional, it attains a flat change for the current sign and continuous (no) change for the voltage sign (in variable-load circumstance). The flat change protects the load from obliteration by high-voltage beats or turbulences.

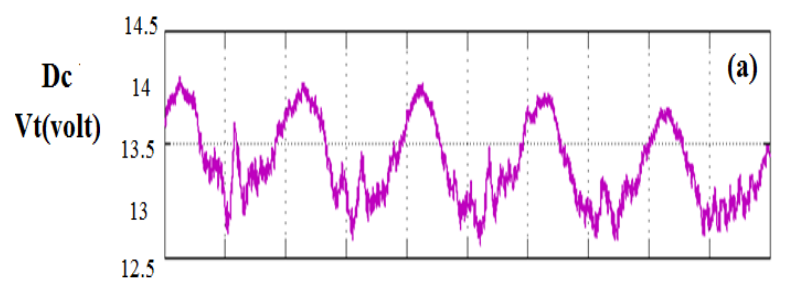

IL
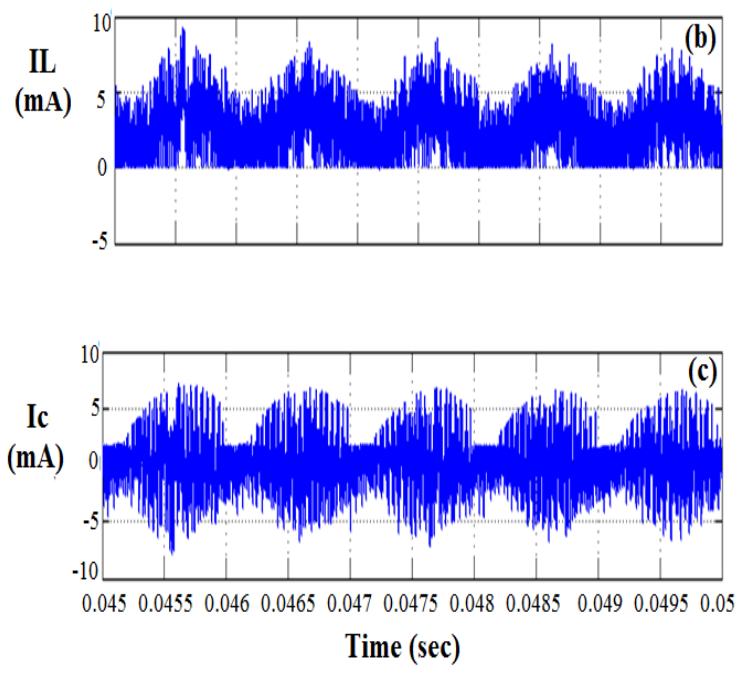

Fig. 9. DC to DC output with Fuzzy controller
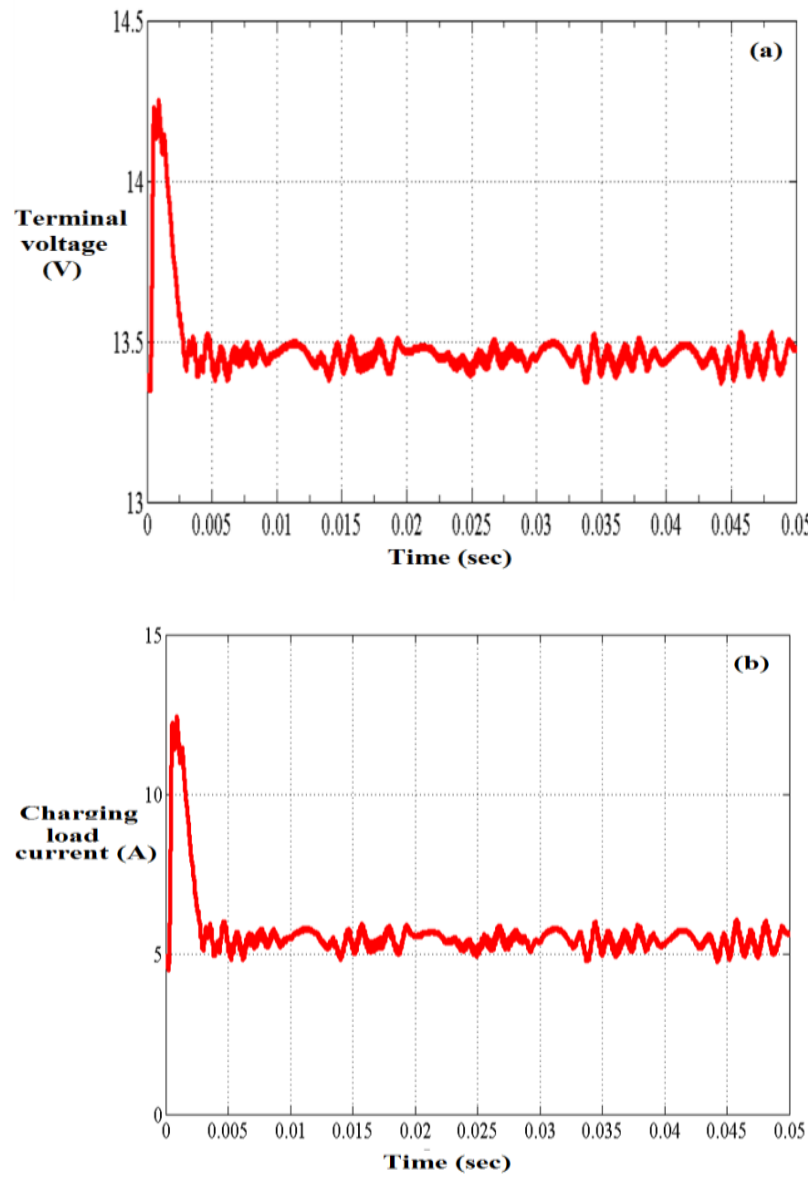

Fig.10. The battery-operated charging output

The design for HSFL-PIDC information transmission as of MATLAB to PLC is approved obtainable in the next means:

\subsection{C/C++ Generation with RTWEC}

RTWEC is an add-on of Mathworks which makes $\mathrm{C} / \mathrm{C}^{++}$code from Simulink subsystems and unlocks the Simulink model. In the blackboard by snapping on "Tools - Real -Time Workshop- Options..." a window is showed with a steering bar. The entry "Actual Workshop" is chosen by evasion. Once the $\mathrm{C} / \mathrm{C}^{++}$code is shaped, the window mechanically closes "Build Code for Subsystem". The produced code is located in the directory of the Simulink model"... PID_HSFL-PIDC_disc_rtw" as shown in Fig. 11. 

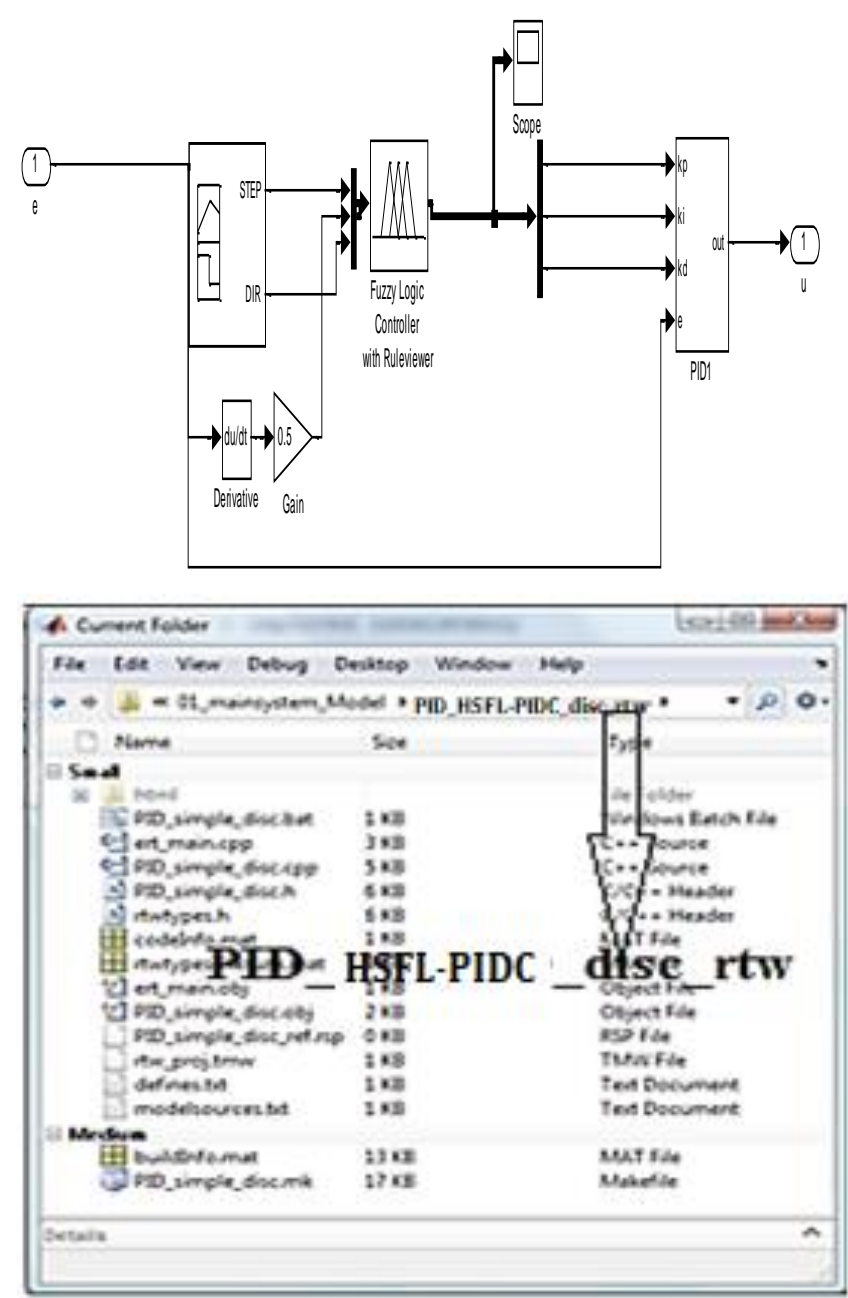

Fig. 11.Characteristic code for scheming PID_HSFL-PIDC skillful systems

\subsection{Wines Simulink / ODK (S2O) Sorcerer}

Wines S2O Sorcerer mechanically makes altogether obligatory chunks, and records for the addition of the Simulink subsystem into a STEP 7 scheme. An SCL basis and a DLL\&RTDLL file are shaped from the made $\mathrm{C} / \mathrm{C}++$ code of RTWEC. The addition is done with STEP 7 V5.x packages finished WinAC S2O Sorcerer. Lastly, the charging of STEP 7 package with DLL\&RTLL is managed to a PC scheme by means of WinAC RTX. In adding, the WinAC ODK Library is combined in the SIMATIC Administrator that needs packages SFB65001 (CREA_COM) and SFB65002 (EXEC_COM) for performing DLL/RTDLL.

\subsection{Configuration with SIMATIC Manager STEP 7 V5.5}

The file ".. \HSFL-PIDC_STEP7_V5x_Project" covers the scheme for STEP7 V5.5 with the next contents:

i. WinAC RTX is the lone the hardware formation of PC position with WinAC
RTX helps as a pattern and the package is unfilled.

ii. PID_HSFL-PIDC delivers a ready program for addition finished the WinAC S2O Sorcerer. The next blocks are concurrently shaped:

- OB35 (CYC_INT5) as recurring OB with $100 \mathrm{~ms}$ cycle. The fake skillful scheme and the PID manager (PID_HSFL-PIDC_disc) are named in this chunk.

- DB35 (Data) as a worldwide data chunk that covers all obligatory variables such as Setpoint [Real] \& PID_output [Real].

- Process_value [Real], crea_status [Word] (delivers the location via CREA_COM), exec_status [Word] (delivers the position via EXEC_COM) and reset [Bool].

- FB100 (PROC_C) with Instanz-DB100 Simulated PT3 process (parameterized like the procedure in MATLAB/Simulink).

- SFB65001 (CREA COM) for initialization of the DLL/RTDLL file.

- SFB65002 (EXEXC_COM) for application of the DLL/RTDLL file.

- VAT_1 Changeable bench with the variables of DB35 (DATA).

The steps obligatory to whole the package "PID_HSFL-PIDC" with the "PID_HSFL-PIDC disc" block from the WinAC S2O Wizard are portrayed in Fig. 12.

Network 2 : PID_HSFL-PIDC

\section{PID-GNFPID Function Block from Simulink}

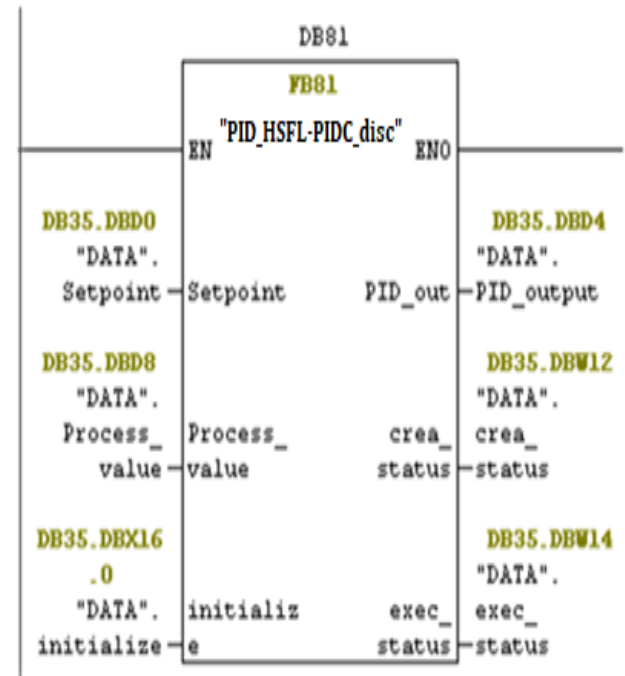

Fig. 12.The FB PID HSFL-PIDC disc" into the "Network 2: PID Controller 


\subsection{SIMATIC Manager Opening}

To start with, the instance scheme "S2O_PID_HSFL-PIDC" in the almanac "... HSFLPIDC_STEP7_V5x_Project" is opened. As labeled beforehand, throughout the implementation of the WinAC SO2 Sorcerer, the SCL foundation "PID_HSFL-PIDC_disc" is previously been combined and the purpose block ("PID_HSFLPIDC disc") is formed. Initial of $\mathrm{OB} 35$ and supplement of "FB PID_HSFL-PIDC_disc" addicted to the "Network 2: PID Controller" is done.Inputs and productions intersect are exposed in the Fig. 12. Insufficient ladders such as filling the package to the WinAC RTX, repetition the DLL (C_ODK.dll) or RTDLL (C_ODK.rtdll) addicted to the almanac C: $\backslash$ of the PC scheme with the WinAC RTX, registration RTDLL files and location the WinAC into the RUN style are wanted to be approved out.

\subsection{Implementation}

The next ladders are performed for ordering afterward charging the package to WinAC-RTX: Open the "VAT_1" mutable bench, Click the icon "Display Adjustable", Variation the value of the mutable "prepare" to "TRUE" and get on the icon "Adjust Mutable". Alteration the rate of the mutable "prepare" to "FALSE" and then get on the icon "Adapt Adjustable". Alteration the rate of the mutable "Established point" to a wanted charge, e.g. 50 , and get on the icon "Modify Variable". The HSFL-PIDC manager makes an output due to the alteration of the established point. The procedure therefore fluctuations pending the "Established point" is rehabilitated as exposed in Fig. 13.

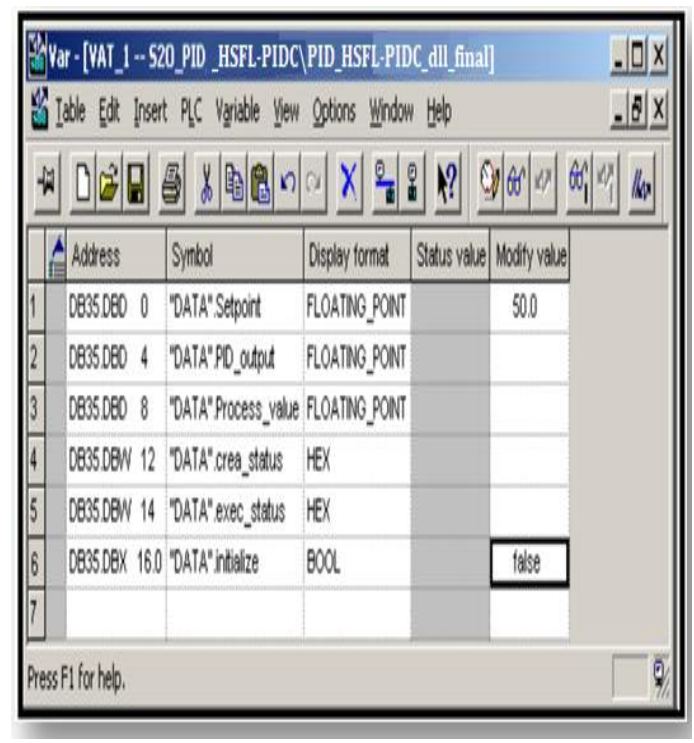

Fig. 13.The variable table VAT_1

\subsection{HSFL-PIDC-PLC Controller}

The PLC (HSFL-PIDC) controller hardware fitting is approved out by means of SIMATIC IPC427C (MICROBOX PC) and S7 package is laden with the quantified formation, such as $\mathrm{PG} / \mathrm{PC}$ border: Ethernet (192.168.2.200) and IPC427C border: PROFINET CP1616 (192.168.2.10). For a comparison of our results, secure, HSFL-PIDC manager is active without HSFL-PIDC (following with Arduino) manager.

Table 6.The experimental results

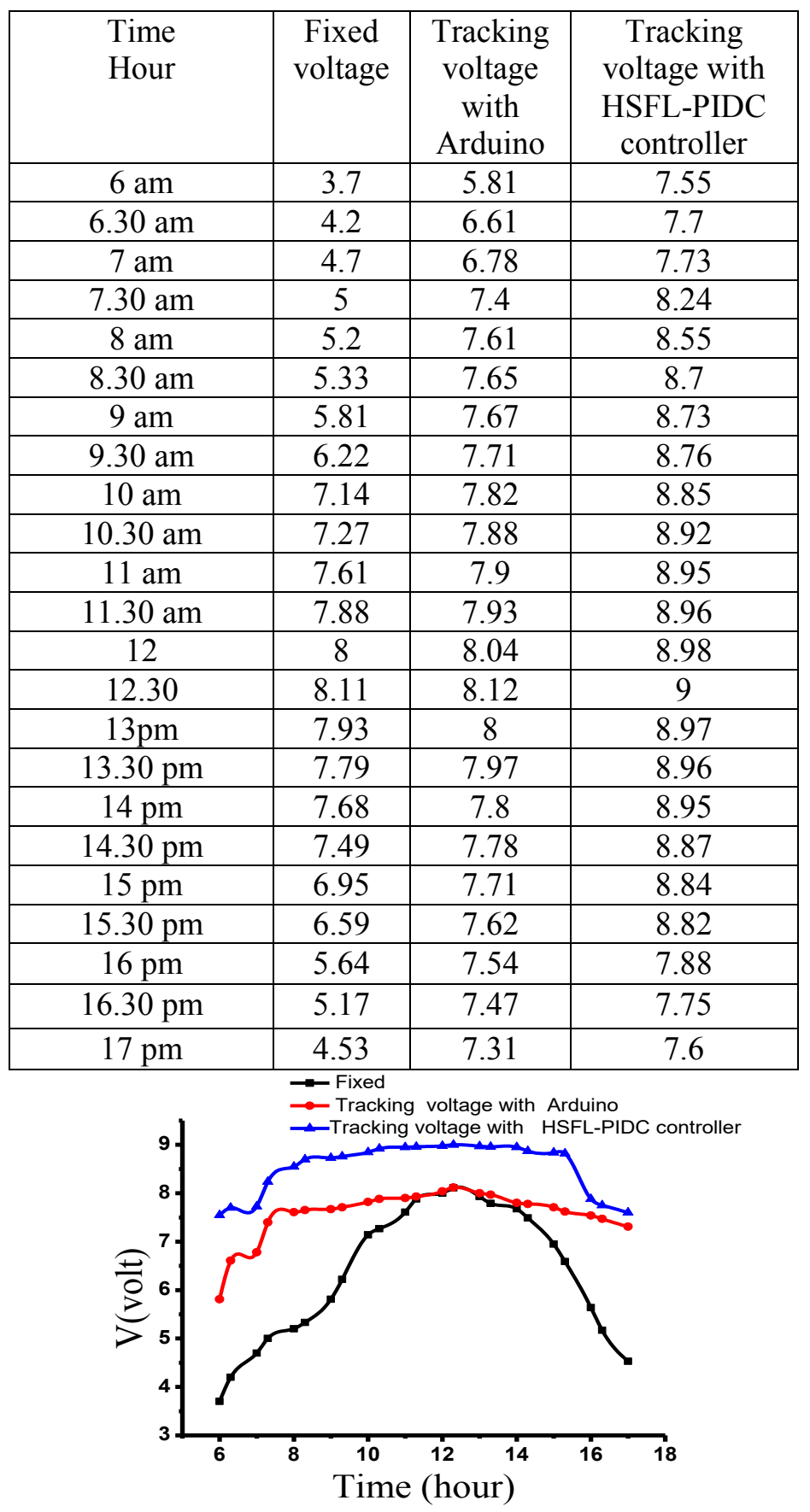

Fig. 14. Seen contrast of the general technique of Fixed (manual tracing), tracing voltage with 
Arduino and tracing voltage with HSFL-PIDC controller

\subsection{Comparison of HSFL-PIDC with Other Related Works}

Understood evaluation of the general technique of Fixed (manual tracing ), tracing voltage with Arduino and tracing voltage with HSFL-PIDC controller a showing in Fig. 14 .The tracking voltage with HSFL-PIDC controller a viewing is very good cooperation the two other techniques. It is obvious that the projected HSFL-PIDC situated the MPPT of the PV component actual near to the theoretic rate as likened to the traditional PSO process and ANN as showing in Fig. 15.whreas our technique have ftearuse for control ability for power more the traditional PSO process and ANN

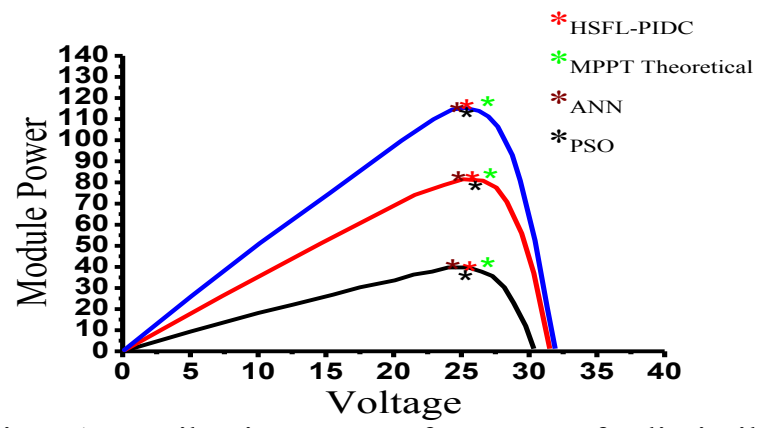

Fig. 15. Likening P-V features of dissimilar approaches

Fig. 16 demonstrations the battery-operated charging voltage difference of the $1 \mathrm{~A}-3 \mathrm{P} \mathrm{PV}$, the immovable PV and following with HSFL-PIDC throughout the day.It is present that the upsurge of monthly-total power generation from HSFL-PIDC sun tracking $\mathrm{PV}$ is experiential to be in between $13.41 \%$ and $303.26 \%$. The effectiveness of solar cells is released from $11.6 \%$ to $10.4 \%$ while the temperature is augmented from 38 to $48 \mathrm{oC}$ and the concentration of dust per month was projected at 0.0618 .

on the other hand our technique have features that needs for battery charging voltage of overall technique because it have the best battery charging voltage comparison with other techniques likes Fixed PV, tracking voltage with 1A-3P PV, and also the efficacy and power generation as exposed in Figures 16.17 and 18.

[28]Humidity touches the solar cells in one method or another associated to dust gatherers. The effect of humidity is reduced through the movement of the solar cell, followed the sun depends on the MMPPT technique from morning to evening, and this continuous movement prevents the gathering of dust or moisture and reduces its effect.

[47] Thus, the projected HSFL-PIDC procedure is well-organized under dissimilar standards of solar radiation as in Fig. 17. Table 6 enlists the presentation of the projected method when likened with five other recognized MPPT approaches. The difference of daily control generation is improved for solar tracing with HSFL-PIDC and solar radiation in the long-term examination as displayed in Fig. 18. It is further experiential that power generation is augmented beyond $30.1829 \%$ as predictable in sunlit days [48].The battery voltage of the immovable PV is a minor bit lesser than that of the 1A-3P PV temporarily the power generation of the immovable PV is fewer than the 1A-3P PV, while the projected HSFL-PIDC contrast with overall approaches gives development of MPPT [49].[47, 50]It is experiential that the reply of an MPPT scheme with new HSFL-PIDC manager is extremely sensitive for a very slight alteration as portrayed in Fig.14, 15, 16.17,18. [47]By likening our results with the following voltage of Arduino manual and HSFL-PIDC it is found that the projected HSFL-PIDC controller has least settling time, less rise time and steady-state error.

The reference review paper [51, 52] proposal aids such as improved efficiency depends on tracking accurateness and the energy conversion efficiency,in addition to that improving Solar PV Scheme that proposed by [53] have been emphasize and admit that the power generation of solar PV can be increased using sun tracking technology . whereas the our projected HSFL-PIDC contrast with overall methods gives progress of MPPT. It is experiential that the response of an MPPT system with new HSFL-PIDC controller is highly sensitive for a very minor change whereas the system sensitive for any affected may be light intensity and temperatures Humidity touches the solar cells and the place solar cells and direction. Because of response to any small changes the proposed HSFL-PIDC controller scheme is established to achieve an overall king increase from about $10 \%$ to $50 \%$ more than other techniques.

This paper important to power quality because of renewable energy is the energy derived from natural resources that are renewed, i.e. those that are not depleted. They are fundamentally different from the fossil fuels of petroleum, coal, and natural gas, or nuclear fuel that is used in nuclear reactors. Renewable energy usually does not generate waste such as carbon dioxide (CO2) or harmful gases, or it 
increases global warming as occurs when combustion of fossil fuels or harmful atomic waste resulting from nuclear reactors. Renewable energy is produced from wind, water and the sun. It can also be produced from the movement of waves and tides, or from geothermal energy, as well as from agricultural crops and oil-producing trees.

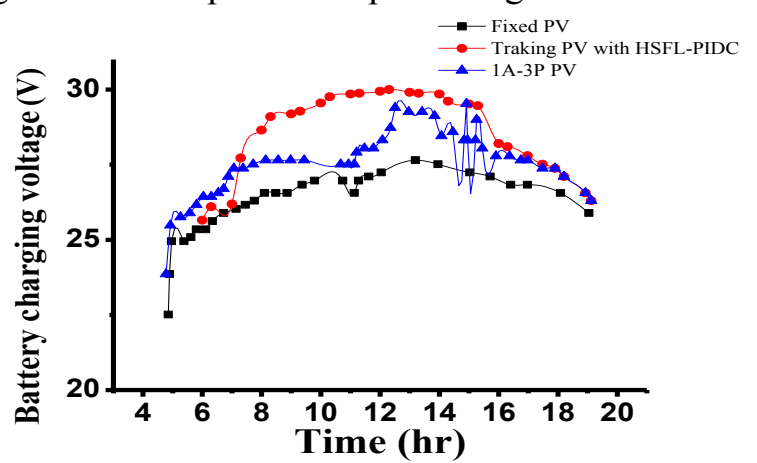

Fig. 16. Contrast of battery charging voltage of overall technique of Fixed PV[49], tracking voltage with 1A-3P PV[1] and following voltage with HSFL-PIDC.

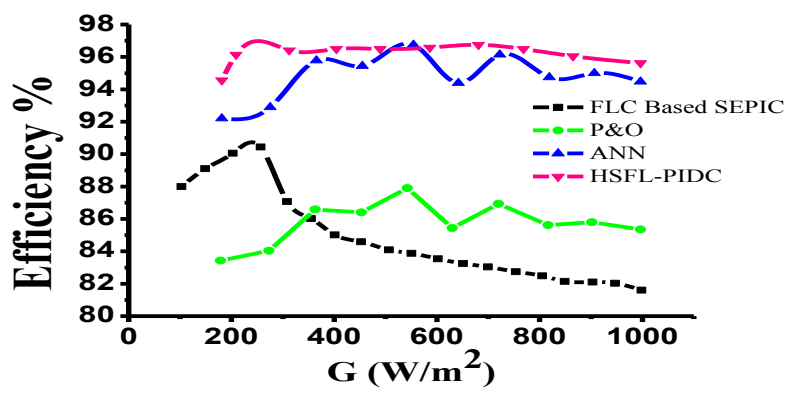

Fig. 17. Likening efficacy of the projected PV scheme with other approaches.

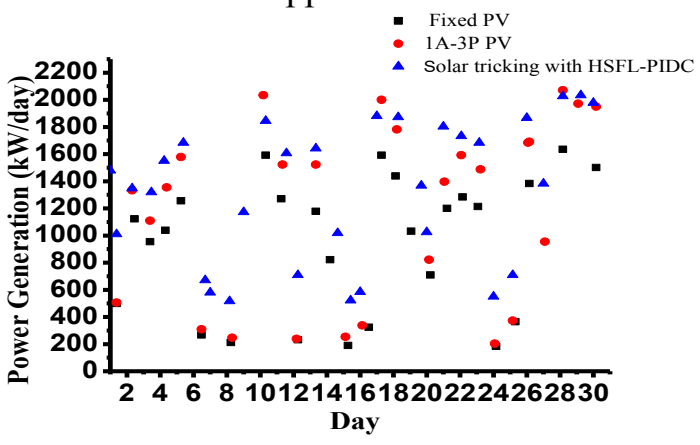

Fig. 18. Long-term test results of 1A-3P following $\mathrm{PV}$, fixed PV and following voltage with HSFLPIDC approaches.

\section{Conclusion}

- A novel solar following system is projected and applied to recover the energy achievement of solar control power plants.

- The dual-axis tracing scheme attained the highest energy improvement in every area and obtainable as the most versatile schemes. Furthermore, consequences exposed that it can be fitted wherever with certain high energy gain. The PLC (HSFLPIDC) controller hardware fitting is carried out with the stated arrangement such as $\mathrm{PG} / \mathrm{PC}$ interface.

- The presentation of the projected analogimplemented MPPT with HSFL-PIDC controller is estimated by interfacing it with a hardware example of dual photovoltaic (PV) scheme.

- HSFL-PIDC controller is used to regulate the location of servo motors which safeguarded the suitable post on the panel and progress the solar presentation in full term of charging and rectifying.

- The use of LDR sensors and high accuracy angle sensors, shaped more correct and the well-organized following scheme.

- The projected involuntary solar following scheme is established to achieve an overall king increase from about $10 \%$ to $50 \%$ more than the fixed-angle PV scheme.

- The our method finds the actual MPPT in the output characteristic completely dependent of parameter values for solar components and this method is accurate and simple to implement, and shows robust and reliable performance by using RBF-NN to enhancing the rule base of fuzzy controllers.

- The suggested automatic solar tracking system is demonstrated to achieve an overall power increase more than the fixedangle PV, 1A-3P PV, Classical P\&O algorithm and ANN.

- The achievement scheme is established to be effectual and robust in refining solar charging and rectifying range.

- The ideas about future research in this area may be dependents on the to achieve an overall king increase up to $50 \%$ more than the fixed-angle PV scheme, 1A-3P PV, Classical $\mathrm{P} \& \mathrm{O}$ algorithm and ANN and increasing the efficiency of charging and rectifying capacity.

\section{Acknowledgements}

Abdullah is thankful to Dr.S.K.Ghushal for many valuable suggestions and critical readings of the manuscript. 
References

[1] M. Engin and D. Engin, "Optimization mechatronic sun tracking system controller's for improving performance," in 2013 IEEE International Conference on Mechatronics and Automation, 2013: IEEE, pp. 11081112.

[2] M. Zolkapli, S. Al-Junid, Z. Othman, A. Manut, and M. M. Zulkifli, "Highefficiency dual-axis solar tracking developement using Arduino," in Technology, Informatics, Management, Engineering, and Environment (TIME-E), 2013 International Conference on, 2013: IEEE, pp. 43-47.

[3] S. Elagib and N. Osman, "Design and implementation of dual axis solar tracker based on solar maps," in 2013 INTERNATIONAL CONFERENCE ON COMPUTING, ELECTRICAL AND ELECTRONIC ENGINEERING (ICCEEE), 2013.

[4] M. A. J. Paul, "Design and performance analysis of automated two axis solar tracking system for steam generation," in Energy Efficient Technologies for Sustainability (ICEETS), 2013 International Conference on, 2013: IEEE, pp. 432-437.

[5] W. Chen, M. Xing, and K. Fang, "A PLCbased fuzzy PID controller for pressure control in Coke-oven," in Control Conference (CCC), 2012 31st Chinese, 2527 July 2012 2012, pp. 4754-4758.

[6] L. Ma, K. Y. Lee, and Z. Wang, "Intelligent coordinated controller design for a $600 \mathrm{MW}$ supercritical boiler unit based on expandedstructure neural network inverse models," Control Engineering Practice, vol. 53, pp. 194-201, 2016.

[7] A. O'Dwyer, Handbook of PI and PID controller tuning rules. Imperial college press, 2009.

[8] N. D. Pandey and P. Tiwari, "Comparison between Speed Control DC Motor Using Genetic Algorithm and PSO-PID Algorithm," International Journal of Electrical Engineering \& Technology, vol. 8, no. 1, pp. 17-25, 2017.

[9] H. E. Kalhoodashti and M. Shahbazian, "Hybrid speed control of induction motor using PI and fuzzy controller," International Journal of Computer Applications, vol. 30, no. 11, pp. 44-50, 2011.
[10] M. R. Douiri, M. Cherkaoui, and A. Essadki, "Genetic algorithms based fuzzy speed controllers for indirect field oriented control of induction motor drive,"

International Journal of Circuits, Systems and Signal Processing, vol. 6, no. 1, pp. 2128, 2012.

[11] M. Ranjani and P. Murugesan, "Optimal fuzzy controller parameters using PSO for speed control of Quasi-Z Source DC/DC converter fed drive," Applied Soft Computing, vol. 27, pp. 332-356, 2015.

[12] A. Lotfy, M. Kaveh, M. Mosavi, and A. Rahmati, "An enhanced fuzzy controller based on improved genetic algorithm for speed control of DC motors," Analog Integrated Circuits and Signal Processing, pp. 1-15, 2020.

[13] P. Kumar and D. Dohare, "Comparison of performance measures of speed control for a DC Motor using Fuzzy Logic Controller and Optimal LQR Controller," IJSTEInternational Journal of Science Technology \& Engineering, vol. 3, no. 11, 2017.

[14] Z. L. A, " Fuzzy sets,Information and Control," vol. 8:338-353, 1965.

[15] N. Farouk and B. Tian, "Application of self-tuning fuzzy PID controller on the AVR system," in Mechatronics and Automation (ICMA), 2012 International Conference on, 5-8 Aug. 2012 2012, pp. 2510-2514, doi: 10.1109/ICMA.2012.6285741.

[16] O. D. A, Handbook of PI and PID controller tuning rules. 2003.

[17] R. A. a. D. K. Baskarn, " Speed Control of Induction Motor Using Fuzzy PI and Optimized Using GA," International Journal of Recent Trends in Engineering, vol. 2, no. 5, 2009.

[18] D. P. P. Neenu Thomas, "Position Control of DC Motor Using Genetic Algorithmbased PID Controller," London, U.K Proceedings of the World Congress on Engineering, vol. 2, no. WCE 2009, 2009.

[19] C.-D. Lee, H.-C. Huang, and H.-Y. Yeh, "The development of sun-tracking system using image processing," Sensors, vol. 13, no. 5, pp. 5448-5459, 2013.

[20] S. Ahmad, S. Shafie, and M. Z. A. Ab Kadir, "A high power generation, low power consumption solar tracker," in Power and Energy (PECon), 2012 IEEE 
International Conference on, 2012: IEEE, pp. 366-371.

[21] X. Zhang, X. Li, and K. Lu, "Research on an intelligent solar tracking system based on LPC2131," in 2012 3rd IEEE International Conference on Network Infrastructure and Digital Content, 2012: IEEE, pp. 429-432.

[22] F. Xie and G. Zhang, "Simulation and Analysis of Computer Control Tracking System Based on Solar Geometric for Fresnel Lenses Concentration Photovoltics," in Intelligent Human-Machine Systems and Cybernetics (IHMSC), 2011 International Conference on, 2011, vol. 1: IEEE, pp. 101104.

[23] Z. Li and R. Zhou, "Sun tracker design based on AVR," in Power and Energy Engineering Conference (APPEEC), 2011 Asia-Pacific, 2011: IEEE, pp. 1-4.

[24] F. Shama, G. H. Roshani, A. Ahmadi, and S. Roshani, "A Novel Design and Experimental Study for a Two-Axis Sun Tracker," in Power and Energy Engineering Conference (APPEEC), 2011 Asia-Pacific, 2011: IEEE, pp. 1-4.

[25] S. Seme, G. Stumberger, and J. Voršič, "Maximum efficiency trajectories of a twoaxis sun tracking system determined considering tracking system consumption," IEEE Transactions on power electronics, vol. 26, no. 4, pp. 1280-1290, 2011.

[26] Siemens, SIMATIC WinAC S2O Wizard February 2012

[27] H.-C. Lu and T.-L. Shih, "Fuzzy system control design with application to solar panel active dual-axis Sun tracker system," in Systems Man and Cybernetics (SMC), 2010 IEEE International Conference on, 2010: IEEE, pp. 1878-1883.

[28] A. Al Nabulsi, A. El Nosh, A. Ahli, M. Sulaiman, and R. Dhaouadi, "Efficiency optimization of a 150W PV system using dual axis tracking and MPPT," in Energy Conference and Exhibition (EnergyCon), 2010 IEEE International, 2010: IEEE, pp. 400-405.

[29] S. Xiaofang and G. Wencheng, "A Sun Spot Center Orientation Method Based on Ellipse Fitting in the Application of CPV Solar Tracker," in Intelligent System Design and Engineering Application (ISDEA), 2010 International Conference on, 2010, vol. 1: IEEE, pp. 175-178.

[30] L. L. Oo and N. K. Hlaing, "Microcontroller-based two-axis solar tracking system," in Computer Research and Development, 2010 Second International Conference on, 2010: IEEE, pp. 436-440.

[31] S. Dasgupta, F. W. Suwandi, S. Sahoo, and S. Panda, "Dual axis sun tracking system with PV cell as the sensor, utilizing hybrid electrical characteristics of the cell to determine insolation," in 2010 IEEE International Conference on Sustainable Energy Technologies (ICSET), 2010: IEEE, pp. 1-5.

[32] H. Jiao, J. Fu, Y. Li, and J. Lai, "Design of automatic two-axis sun-tracking system," in 2010 International Conference on Mechanic Automation and Control Engineering, 2010.

[33] K. Santhosh, T. Dutta, and J. Rajshekar, "2 D tracking system for solar panels using SVM implemented by motion assistant of LabVIEW," in 2013 International Conference on Signal Processing, Image Processing \& Pattern Recognition, 2013: IEEE, pp. 243-247.

[34] N. Kuttybay et al., "An automated intelligent solar tracking control system with adaptive algorithm for different weather conditions," in 2019 IEEE international conference on automatic control and intelligent systems (I2CACIS), 2019: IEEE, pp. 315-319.

[35] L. Yao-Lun, T. Chia-Chang, J. Wu-Shun, and L. Shuen-Jeng, "Design an Intelligent Neural-Fuzzy Controller for Hybrid Motorcycle," in Fuzzy Information Processing Society, 2007. NAFIPS '07. Annual Meeting of the North American, 2427 June 2007 2007, pp. 283-288, doi: 10.1109/nafips.2007.383852.

[36] S. M. S. S.N. Qasem, "Memetic Elitist Pareto Differential Evolution algorithm based Radial Basis Function Networks for classification problems," Applied Soft Computing, vol. 11, no. 1, pp. 5565-5581., 2011.

[37] S. M. S. S.N. Qasem, "Radial basis function network based on time variant multiobjective particle swarm optimization for medical disease diagnosis," Applied Soft Computing, vol. 11, no. 1, pp. 1427-1438, 2011.

[38] M. A. M. P. N. A. Al-geelani, R. Q. Shaddad "Characterization of acoustic signals due to surface discharges on H.V. glass insulators using wavelet radial basis function neural networks " Applied Soft 
Computing, vol. 7, no. 2, pp. 1327-1338, 2012.

[39] H. Sang Jeen, G. S. May, and P. DongCheol, "Neural network modeling of reactive ion etching using optical emission spectroscopy data," Semiconductor Manufacturing, IEEE Transactions on, vol. 16 , no. 4 , pp. $598-608,2003$, doi: 10.1109/tsm.2003.818976.

[40] M.-W. K. Shu-Kun Zhao, Yi-Seul Han, SeYoun Jeon, Yun-Keun Lee, and Seung-Soo Han, " Radial Basis Function Network for Endpoint Detection in Plasma Etch Process," Springer-Verlag, vol. 67, pp. 253263, 2010.

[41] R. Khanna, Q. Zhang, W. E. Stanchina, G. F. Reed, and Z.-H. Mao, "Maximum power point tracking using model reference adaptive control," IEEE Transactions on power Electronics, vol. 29, no. 3, pp. 14901499, 2014.

[42] P. T. Krein, "Ripple correlation control, with some applications," in Circuits and Systems, 1999. ISCAS'99. Proceedings of the 1999 IEEE International Symposium on, 1999, vol. 5: IEEE, pp. 283-286.

[43] D. Logue and P. Krein, "Optimization of power electronic systems using ripple correlation control: A dynamic programming approach," in Power Electronics Specialists Conference, 2001. PESC. 2001 IEEE 32nd Annual, 2001, vol. 2: IEEE, pp. 459-464.

[44] J. W. Kimball and P. T. Krein, "Discretetime ripple correlation control for maximum power point tracking," IEEE Transactions on Power Electronics, vol. 23, no. 5, pp. 2353-2362, 2008.

[45] D. Devaraj and B. Selvabala, "Real-coded genetic algorithm and fuzzy logic approach for real-time tuning of proportional-integral - derivative controller in automatic voltage regulator system," Generation, Transmission \& Distribution, IET, vol. 3, no. 7, pp. 641-649, 2009, doi: 10.1049/ietgtd.2008.0287.

[46] R. A. Jackey, "A simple, effective lead-acid battery modeling process for electrical system component selection," SAE Technical Paper, 0148-7191, 2007.

[47] M. A. Younis, T. Khatib, M. Najeeb, and A. M. Ariffin, "An improved maximum power point tracking controller for PV systems using artificial neural network," Przeglad
Elektrotechniczny, vol. 88, no. 3b, pp. 116121, 2012.

[48] S.-A. L. a. H.-Y. W. Ching-Chang Wong*, "optimal PID Controller Design for AVR System " Tamkang Journal of Science and Engineering, vol. 12, no. 3, pp. 259-270, 2009.

[49] B. Huang, W. Ding, and Y. Huang, "Longterm field test of solar PV power generation using one-axis 3-position sun tracker," Solar Energy, vol. 85, no. 9, pp. 1935-1944, 2011.

[50] A. El Khateb, N. A. Rahim, J. Selvaraj, and M. N. Uddin, "Fuzzy-logic-controller-based SEPIC converter for maximum power point tracking," IEEE Transactions on Industry Applications, vol. 50, no. 4, pp. 2349-2358, 2014.

[51] W. Nsengiyumva, S. G. Chen, L. Hu, and $\mathrm{X}$. Chen, "Recent advancements and challenges in Solar Tracking Systems (STS): A review," Renewable and Sustainable Energy Reviews, vol. 81, pp. 250-279, 2018/01/01/ 2018, doi: https://doi.org/10.1016/j.rser.2017.06.085.

[52] V. Sumathi, R. Jayapragash, A. Bakshi, and P. Kumar Akella, "Solar tracking methods to maximize PV system output - A review of the methods adopted in recent decade," Renewable and Sustainable Energy Reviews, vol. 74, pp. 130-138, 2017/07/01/ 2017, doi: https://doi.org/10.1016/j.rser.2017.02.013. [53] B.-J. Huang, Y.-C. Huang, G.-Y. Chen, P.C. Hsu, and K. Li, "Improving Solar PV System Efficiency Using One-Axis 3Position Sun Tracking," Energy Procedia, vol. 33, pp. 280-287, 2013/01/01/ 2013, doi: https://doi.org/10.1016/j.egypro.2013.05.06 $\underline{9}$.

\section{Creative Commons Attribution License 4.0} (Attribution 4.0 International, CC BY 4.0)

This article is published under the terms of the Creative Commons Attribution License 4.0 https://creativecommons.org/licenses/by/4.0/deed.en_US 